Check for updates

Cite this: RSC Adv., 2019, 9, 9792

Received 11th February 2019

Accepted 14th March 2019

DOI: 10.1039/c9ra01086f

rsc.li/rsc-advances

\section{Selected pharmaceuticals removal using algae derived porous carbon: experimental, modeling and DFT theoretical insights $\uparrow$}

\author{
N. Ouasfi, ${ }^{\text {ad }}$ M. Zbair, (D) ${ }^{* b}$ S. Bouzikri, ${ }^{a}$ Z. Anfar, (D) ${ }^{c}$ M. Bensitel, ${ }^{b}$ H. Ait Ahsaine, (D) $^{c}$ \\ E. Sabbard and L. Khamliche*a
}

Porous carbon from Laminaria digitata algae activated using $\mathrm{NaOH}$ (PCLD@NaOH) was prepared by a chemical activation approach and has been tested for the adsorption of ketoprofen and aspirin molecules. The prepared PCLD@NaOH was characterized using XPS, FTIR, Raman, $\mathrm{N}_{2}$-physisorption, SEM, acidic/basic character (Boehm), and $\mathrm{pH}_{\text {PzC }}$. The batch adsorption of ketoprofen and aspirin was investigated under different parameters. The adsorption kinetics on PCLD@NaOH were well described by the Avramifractional kinetic model and the equilibrium data by Liu isotherm model. The adsorption capacity of aspirin (970.88 $\mathrm{mg} \mathrm{g}^{-1}$ at $25^{\circ} \mathrm{C}$ ) was higher than ketoprofen $\left(443.45 \mathrm{mg} \mathrm{g}^{-1}\right.$ at $25^{\circ} \mathrm{C}$ ). The thermodynamic values indicate that the adsorption of ketoprofen and aspirin is exothermic and spontaneous. These results were in good agreement with DFT calculation that shows that the aspirin molecule presents high reactivity, electrophilicity, and softness compared to the ketoprofen molecule. Finally, the response surface methodology was used to optimize the removal efficiency of ketoprofen and aspirin.

\section{Introduction}

Drugs play a key role in improving the quality and life expectancy of populations. Each year, thousands of tons of pharmaceuticals are used in human and veterinary medicine to treat symptoms, illnesses, bacterial infections, stress and to prevent pregnancy and stimulate the growth of farm and aquaculture. ${ }^{\mathbf{1 2}}$ Pharmaceutical substances are produced and consumed in very large quantities around the world. Their use is an origin of generalized contamination of the different areas of our environment by a broad spectrum of molecules. Some of them are persistent and their accumulation can be toxic for humans as well as for all living beings. ${ }^{3-7}$

\footnotetext{
${ }^{a}$ Laboratory of Organic Chemistry, Bioorganic and Environment, Chemistry Department, Faculty of Science, University Chouaib Doukkali, El Jadida, Morocco. E-mail: khamliche@yahoo.fr

${ }^{b}$ Laboratory of Catalysis and Corrosion of Materials (LCCM), Department of Chemistry, Faculty of Sciences of El Jadida, University of Chouaïb Doukkali, BP 20, 24000 El Jadida, Morocco. E-mail: zbair.mohamed@gmail.com

${ }^{c}$ Laboratoire Matériaux et Environnement LME, Faculté des Sciences, Université Ibn Zohr, BP 8106, Cité Dakhla, Agadir, Morocco

${ }^{d}$ Laboratory of Physico-Chemistry of Materials (LPCM), ChemistryDepartment, Faculty of Sciences, University of Chouaïb Doukkali, El Jadida, Morocco

$\dagger$ Electronic supplementary information (ESI) available. See DOI: 10.1039/c9ra01086f

\$ Present address: KAUST Catalysis Center (KCC) and Physical Sciences and Engineering Division (PSE), King Abdullah University of Science and Technology (KAUST), 4700 KAUST, Thuwal 23955-6900, Saudi Arabia.
}

Among these drugs, aspirin and ketoprofen molecules which are considered as non-steroidal anti-inflammatory drugs (NSAIDs) are most frequently found due to their widespread use. ${ }^{8,9}$ While there is no sign to suggest that NSAIDs are risky to adults, they may be toxic to aquatic organisms and harmful to embryos, infants, children, and adults with feeble constitutions and sensitivity to pharmaceuticals and these drugs have been found in surface water and also in some samples of drinking water. ${ }^{\mathbf{1 0 - 1 4}}$ In Africa, ketoprofen was detected in all wastewater samples at a range of 1.2 to $9.0 \mu \mathrm{g} \mathrm{L}^{-1}$ and in some river water samples (Mbokodweni River south of Durban, South Africa). ${ }^{\mathbf{1 5}}$ Furthermore, aspirin and ketoprofen were the most abundant pharmaceutical observed, $118 \mu \mathrm{g} \mathrm{L}^{-1}$ of aspirin and $3.15 \mu \mathrm{g} \mathrm{L}^{-1}$ of ketoprofen in wastewater influent (Msunduzi River in the province of KwaZulu-Natal, South Africa). ${ }^{16}$ In addition, Silindile et al., reported that the concentrations of ketoprofen in the influent and effluent samples (Durban in KwaZulu-Natal Province of South Africa) were in the ranges of 22.5-34.0 and 1.14-5.33 $\mu \mathrm{g} \mathrm{\textrm {L } ^ { - 1 }}$, respectively. ${ }^{17}$

To date, several approaches, such as degradation, ${ }^{\mathbf{1 8}}$ ozonation, ${ }^{19}$ electrocoagulation, ${ }^{10,20}$ electrochemical, ${ }^{21}$ adsorption ${ }^{22,23}$ and so on, have been studied for the removal of NSAIDs drugs from aqueous solution. In contrast to other approaches, adsorption is considered as effective and economical ways for the elimination of NSAIDs from waters. ${ }^{\mathbf{1 4 2 2 , 2 4 , 2 5}}$ Porous and functional carbon materials have drawn huge attention for environmental remediation determinations owing to their high porosity and tenability. ${ }^{\mathbf{2 6 - 3 0}}$ Several crud materials have been used to prepare porous materials such as Cassia fistula 
(commonly known as golden shower; GS), ${ }^{31}$ corncob wastes, ${ }^{32}$ jujube seed, ${ }^{33}$ almond shell, ${ }^{34}$ with high adsorption capacity and fast adsorption kinetics.

Recently, algae plant has received great attention as a wastewater treatment material. This may be due to its effectiveness towards removing toxic substances in wastewater and probably that it is environmentally friendly. ${ }^{22,35-37}$

Laminaria digitata (LD) is a brown algae belong to Laminariaceae family. The LD algae are one of the largest algae encountered on the European and North African coast. The size of $\mathrm{LD}$ algae is ranged between 1 to $2 \mathrm{~mm}$ and it lives fixed to the rocks to a depth of 10 meters and thrives in moderately beaten areas or strong currents. Few studies have shown the use of this algae as an adsorbent for the adsorption of toxic metals. ${ }^{38,39}$ To our knowledge, no work has been stated before on the removal of medicinal drugs from water by carbon materials derived from Laminaria digitata (LD).

In the present study, the adsorption ketoprofen and aspirin molecules on the surfaces of porous carbon derived Laminaria digitata prepared by $\mathrm{NaOH}$ (PCLD@NaOH) were conducted; the PCLD@NaOH was synthesized by chemical activation approach and characterized by XPS, FTIR, Raman, N2-physisorption, SEM, acidic/basic character (Boehm), and $\mathrm{pH}_{\mathrm{PZC}}$. Adsorption studies were carried out in a batch system to investigate the removal of ketoprofen and aspirin and optimized using response surface methodology coupled with central composite design. Theoretical studies of chemical reactivity of ketoprofen and aspirin molecules tested were computed using DFT-based descriptors. The effects and influences credited to the characteristics of the PCLD@NaOH and experimental adsorption systems, in addition to the results of the theoretical study of ketoprofen and aspirin molecules were discussed according to the adsorption efficiency.

\section{Materials and methods}

\subsection{Sampling and sample preparation}

The algae Laminaria digitata (LD) is collected from El Jadida, on the West Atlantic coast of Morocco. Once washed, it is dried in the oven at $60^{\circ}$ for 24 hours, and then crushed.

\subsection{Preparation of porous carbon}

The algae Laminaria digitata (LD) were impregnated with sodium hydroxide $(\mathrm{NaOH})$, the weight ratio used was $1: 1$ and the mixture kept in an ultrasonic bath for 6 hours. After, the solid sample was isolated by filtration, and then dried at $80^{\circ} \mathrm{C}$ for $12 \mathrm{~h}$. The obtained product was then pyrolyzed at $600{ }^{\circ} \mathrm{C}$ for 2 hours under a nitrogen atmosphere $\left(60 \mathrm{~mL} \mathrm{~min}^{-1}\right)$. The obtained sample was washed several times by distilled water. The obtained porous carbon material was labeled: PCLD@NaOH. The size of PCLD@NaOH particles used in the adsorption was around $100 \mu \mathrm{m}$.

\subsection{Characterization methods}

XPS analysis was carried out using Thermo Fisher Scientific ESCALAB 250Xi X-ray photoelectron spectroscopy system equipped with $\mathrm{Al} \mathrm{K} \alpha \mathrm{X}$-ray source $(h \nu=1486.7 \mathrm{eV})$ to study the chemical states synthesized PCLD@NaOH. Scanning electron microscopy
(SEM) of PCLD@NaOH using FEI, Quanta 200-ESEM operated at $20 \mathrm{kV}$. The Brunauer-Emmett-Teller (BET) surface area $\left(S_{\mathrm{BET}}\right)$ of PCLD@NaOH was determined by the nitrogen adsorption and desorption isotherm, pore size distribution and specific surface area were measured using a 3Flex physisorption at $77 \mathrm{~K}$. The Fourier Transform Infrared spectra of algae LD and PCLD@NaOH was obtained in the mid-infrared region (500$4000 \mathrm{~cm}^{-1}$ ) using a Shimadzu $4800 \mathrm{~S}$. The spectra were scanned at a resolution of $2.0 \mathrm{~cm}^{-1}$ and with 30 scanning. The ZPC (point of zero charges) of PCLD@NaOH was determined using the $\mathrm{pH}$ drift method. The surface functions of PCLD@NaOH have been determined by the Boehm method. Thus, $0.2 \mathrm{~g}$ of PCLD@NaOH was mixed with $25 \mathrm{~mL}$ of one of the three bases solutions $\mathrm{NaHCO}_{3}(0.05 \mathrm{M}), \mathrm{Na}_{2} \mathrm{CO}_{3}(0.05 \mathrm{M})$ and $\mathrm{NaOH}(0.05 \mathrm{M})$ to identify the organic acid surface groups $(-\mathrm{COOH}),(-\mathrm{COO}-)$ and $(-\mathrm{OH})$, respectively. For basic surface functions, $0.2 \mathrm{~g}$ of PCLD@NaOH was brought into contact with $25 \mathrm{~mL}$ of $0.05 \mathrm{M} \mathrm{HCl}$. After 48 hours of stirring, the solutions were decanted for 4 hours and then filtered, and $10 \mathrm{~mL}\left(V_{\mathrm{a}}\right)$ aliquots were then taken by pipette from the filtrates. The aliquots of the reaction base $\mathrm{NaHCO}_{3}$, $\mathrm{Na}_{2} \mathrm{CO}_{3}$, and $\mathrm{NaOH}$ were acidified by adding of 20,30 , and $20 \mathrm{~mL}$ $\left(V_{\mathrm{HCl}}\right)$ of $\mathrm{HCl}(0.05 \mathrm{M})$, respectively, and then back-titrated with $\mathrm{NaOH}(0.05 \mathrm{M})$. In the meantime, the aliquots of the reaction acid $\mathrm{HCl}$ were titrated directly with $\mathrm{NaOH}(0.05 \mathrm{M})$. Particularly, the titration was done directly after $\mathrm{CO}_{2}$ expulsion for $2 \mathrm{~h}$ under inert $\mathrm{N}_{2}$ atmosphere, and the degasification was continued during the titration to avoid the $\mathrm{CO}_{2}$ dissolution from the atmosphere.

The endpoint was determined using a methyl red $(0.1 \%)$ color as an indicator. The numbers of moles of PCLD@NaOH surface functionalities were calculated using the equations reported by Tran. ${ }^{40}$

$$
n_{\left(\mathrm{Na}_{2} \mathrm{CO}_{3}\right)}=\frac{2 V_{0}\left[V_{\mathrm{a}} C_{0}-\left(\frac{V_{\mathrm{HCl}} C_{\mathrm{HCl}}-V_{\mathrm{t}(\mathrm{NaOH})} C_{\mathrm{t}(\mathrm{NaOH})}}{2}\right)\right]}{m V_{\mathrm{a}}}
$$

$$
n_{\left(\mathrm{NaOH} / \mathrm{HCO}_{3}\right)}=\frac{V_{0}\left[V_{\mathrm{a}} C_{0}-\left(V_{\mathrm{HCl}} C_{\mathrm{HCl}}-V_{\mathrm{t}(\mathrm{NaOH})} C_{\mathrm{t}(\mathrm{NaOH})}\right)\right]}{m V_{\mathrm{a}}}
$$

$$
n_{(\mathrm{HCl})}=\frac{V_{0}\left[V_{\mathrm{a}} C_{0}-V_{\mathrm{t}(\mathrm{NaOH})} C_{\mathrm{t}(\mathrm{NaOH})}\right]}{m V_{\mathrm{a}}}
$$

where $V_{0}(\mathrm{~mL})$ is the initial added volume of $\mathrm{NaOH} / \mathrm{Na}_{2} \mathrm{CO}_{3} /$ $\mathrm{NaHCO}_{3} / \mathrm{HCl}$ solution; $C_{0}(\mathrm{M})$ is the concentration of $\mathrm{NaOH} /$ $\mathrm{Na}_{2} \mathrm{CO}_{3} / \mathrm{NaHCO}_{3} / \mathrm{HCl}$ when $V_{0}$ is extracted; $V_{\mathrm{HCl}}(\mathrm{mL})$ and $C_{\mathrm{HCl}}$ (M) are the volume and concentration of $\mathrm{HCl}$ solution added to aliquots taken from $V_{0}$, respectively; $V_{\mathrm{a}}(\mathrm{mL})$ is the volume of aliquot taken from $V_{0} ; m(\mathrm{~g})$ is the mass of PCLD@NaOH; and $V_{\mathrm{t}(\mathrm{NaOH})}(\mathrm{mL})$ and $C_{\mathrm{t}(\mathrm{NaOH})}(\mathrm{M})$ are the concentration and volume of the titrant in the back titration, respectively.

\subsection{Adsorption study}

The adsorption process of ketoprofen and aspirin on PCLD@NaOH was run in batch experiments. The effect of PCLD@NaOH mass on ketoprofen and aspirin adsorption was 
studied (concentration $150 \mathrm{mg} \mathrm{L}^{-1}, 60$ min contact time, $\mathrm{pH}$ 3.4, 25 ${ }^{\circ} \mathrm{C}$ ). Notably, the solution $\mathrm{pH}$ was controlled during the experiment using $1 \mathrm{M} \mathrm{NaOH}$ or $1 \mathrm{M} \mathrm{HCl}$, to study the effect of $\mathrm{pH}$ solution on ketoprofen and aspirin adsorption by PCLD@NaOH $\left(150 \mathrm{mg} \mathrm{\textrm {L } ^ { - 1 }}\right.$ initial concentration, $0.02 \mathrm{~g}$ adsorbent, $60 \mathrm{~min}$ contact time, $25^{\circ} \mathrm{C}$ ). Approximately $0.02 \mathrm{~g}$ of PCLD@NaOH was added to $100 \mathrm{~mL}$ of aqueous ketoprofen and aspirin solution $\left(150 \mathrm{mg} \mathrm{L}^{-1}\right)$ and shacked at $200 \mathrm{rpm}$ to study the effect of contact time. After predetermined time intervals, the mixture of PCLD@NaOH and pollutants was directly separated and filtered. The concentration of tested Ketoprofen and aspirin was determined using UV-Vis spectrophotometer spectrometry (Shimadzu-2600) at $\lambda_{\max }=277 \mathrm{~nm}$ and $\lambda_{\max }=$ $281.3 \mathrm{~nm}$, respectively. The adsorption equilibrium experiments of ketoprofen and aspirin onto PCLD@NaOH were carried out at 25, 40 , and $50{ }^{\circ} \mathrm{C}$ using $0.02 \mathrm{~g}$ of PCLD@NaOH and $100 \mathrm{~mL}$ of different concentrations of ketoprofen $\left(20-500 \mathrm{mg} \mathrm{L}^{-1}\right)$ for $1 \mathrm{~h}$.

\subsection{Regeneration}

The regeneration of PCLD@NaOH loaded by aspirin or ketoprofen was regenerated using ethanol. A mass of spent PCLD@NaOH $(0.02 \mathrm{~g})$ was mixed with $50 \mathrm{~mL}$ of ethanol. The mixture was kept under stirring $(150 \mathrm{rpm})$ at room temperature for 3 hours in an orbital shaker. Then, the mixture was filtered and dried at $80{ }^{\circ} \mathrm{C}$ for 6 hours. The regeneration was repeated after each cycle of adsorption experiment.

\subsection{Equations applied in adsorption experiments}

All equations used in this study related to kinetics, equilibrium, and thermodynamics of ketoprofen and aspirin adsorption onto PCLD@NaOH are presented in Table 1

\subsection{DFT-based descriptors calculations}

The reactivity of ketoprofen and aspirin molecule was computed by DFT calculations using Gaussian 5.0.8 program. The optimization of the full geometry of ketoprofen and aspirin was done using B3LYP/6-31G(d) basis set to perform electronic structure calculations. ${ }^{53}$ The geometry of ketoprofen and aspirin was optimized without any symmetry constraint. ${ }^{54}$ The quantum chemical descriptors were obtained from energies linked with the highest occupied molecular orbital (HOMO; $E_{\text {HOMO }}$ ) and lowest unoccupied molecular orbital (LUMO; $\left.E_{\mathrm{LUMO}}\right)$, an energy gap $(\Delta E=$ $\left.E_{\mathrm{LUMO}}-E_{\mathrm{HOMO}}\right)$, the chemical potential $(\mu)$. The general behavior of ketoprofen and aspirin molecules may be analyzed using the global reactivity parameters resulting from DFT like hardness $(\eta$, chemical softness $(S)$, and electrophilicity $(\omega)$, which can be associated with the Frontier orbital energies, hence: ${ }^{55,56}$

$$
\begin{gathered}
\mu=\frac{-\left(E_{\mathrm{HOMO}}+E_{\mathrm{LUMO}}\right)}{2} \\
\eta=\frac{\left(E_{\mathrm{LUMO}}-E_{\mathrm{HUMO}}\right)}{2} \\
S=\frac{1}{\eta}
\end{gathered}
$$

$$
\omega=\frac{\mu^{2}}{2}
$$

Table 1 Equations used in this work to fit the data of adsorption experiments

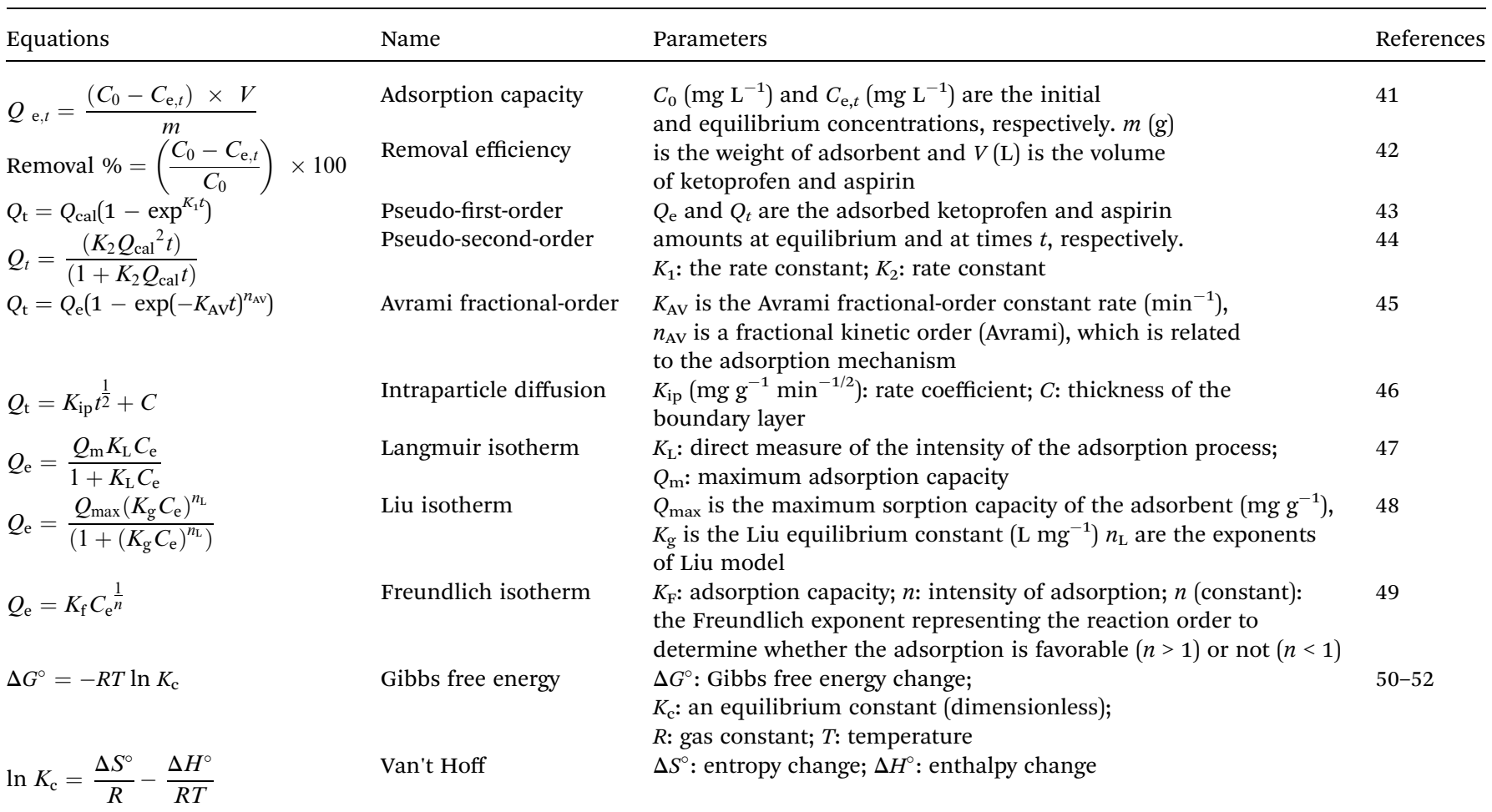




\section{Results and discussion}

\subsection{Characterization of adsorbent}

3.1.1. XPS analysis. The nature of surface functional groups in the PCLD@NaOH is examined in detail by XPS analysis. The XPS survey scan (Fig. 1a) discloses the existence of three peaks $\mathrm{C}$ 1s, $\mathrm{O} 1 \mathrm{~s}$ and $\mathrm{N}$ 1s in the PCLD@NaOH. The high-resolution $\mathrm{C} 1 \mathrm{~s}$ (Fig. 1b) peak divided into 3 components, $\mathrm{C}-\mathrm{C}$ bond $(286.4 \mathrm{eV})$ of $\mathrm{sp}^{3}, \mathrm{O}-\mathrm{C}=\mathrm{O}(289.1 \mathrm{eV})$, and satellite peaks due to $\pi-\pi^{*}$ transitions in aromatic rings exist in PCLD@NaOH (292.0 eV). ${ }^{57,58}$ The deconvolution of XPS O 1s peak of PCLD@NaOH revealed 4 components (Fig. 1c), $\mathrm{C}=\mathrm{O}$ bond $(530.8 \mathrm{eV})$, the peak at $533.6 \mathrm{eV}$ related to ether oxygen atoms in ester and anhydrides, at $535.5 \mathrm{eV}$ is ascribed to the oxygen atoms in the carboxyl groups, and at $537.9 \mathrm{eV}$ is linked to chemisorbed oxygen. ${ }^{59}$ The XPS N 1s spectra of PCLD@NaOH (Fig. 1d) was decomposed into 4 components. The peak shown at $398.2 \mathrm{eV}$ is attributed to pyridinic nitrogen; At $400.4 \mathrm{eV}$ showed the pyrrolic; the pyridinic-N oxides were revealed at $402.2 \mathrm{eV}$, and the contribution of chemisorbed $\mathrm{NO}_{x}$ was observed at $406.3 \mathrm{eV}^{.58-60}$
3.1.2. FTIR analysis and Boehm titration. FTIR spectrum of the PCLD@NaOH adsorbent is presented in Fig. 2a. The characteristics of absorption bands of hydroxyl $(\mathrm{O}-\mathrm{H})$ and amine groups $(\mathrm{N}-\mathrm{H})$ were recognized at $3451 \mathrm{~cm}^{-1}, \mathrm{C}=0$ of the carboxylic groups or ester groups at $1732 \mathrm{~cm}^{-1}$ related to lipids and fatty acids, the located bands around $1492 \mathrm{~cm}^{-1}$ are ascribable to the skeletal vibration of aromatic $\mathrm{C}=\mathrm{C}$ bonds. ${ }^{31}$ Furthermore, the band at $1082 \mathrm{~cm}^{-1}$ confirmed the presence of sulfoxides in the structure of PCLD@NaOH. ${ }^{61}$ Finally, the peak located at $592 \mathrm{~cm}^{-1}$, which belongs to the aromatic $\mathrm{C}-\mathrm{H}$ out-ofplane bending mode, point out the existence of aromatic benzene rings. Furthermore, Table 2 presents quantitative information on the acidic and basic groups on the PCLD@NaOH surfaces; the information was obtained through Boehm titration. Commonly, any adsorbent naturally coexists with both acidic and basic properties in solutions (amphoteric nature). The results show that the prepared adsorbent is rich in acidic groups (3.59 $\left.\mathrm{mmol} \mathrm{g}^{-1}\right)$ and also basic groups $(2.15 \mathrm{mmol}$ $\left.\mathrm{g}^{-1}\right)$.

3.1.3. Raman analysis. Raman analysis of PCLD@NaOH was also performed and is showed in Fig. 2b. The Raman
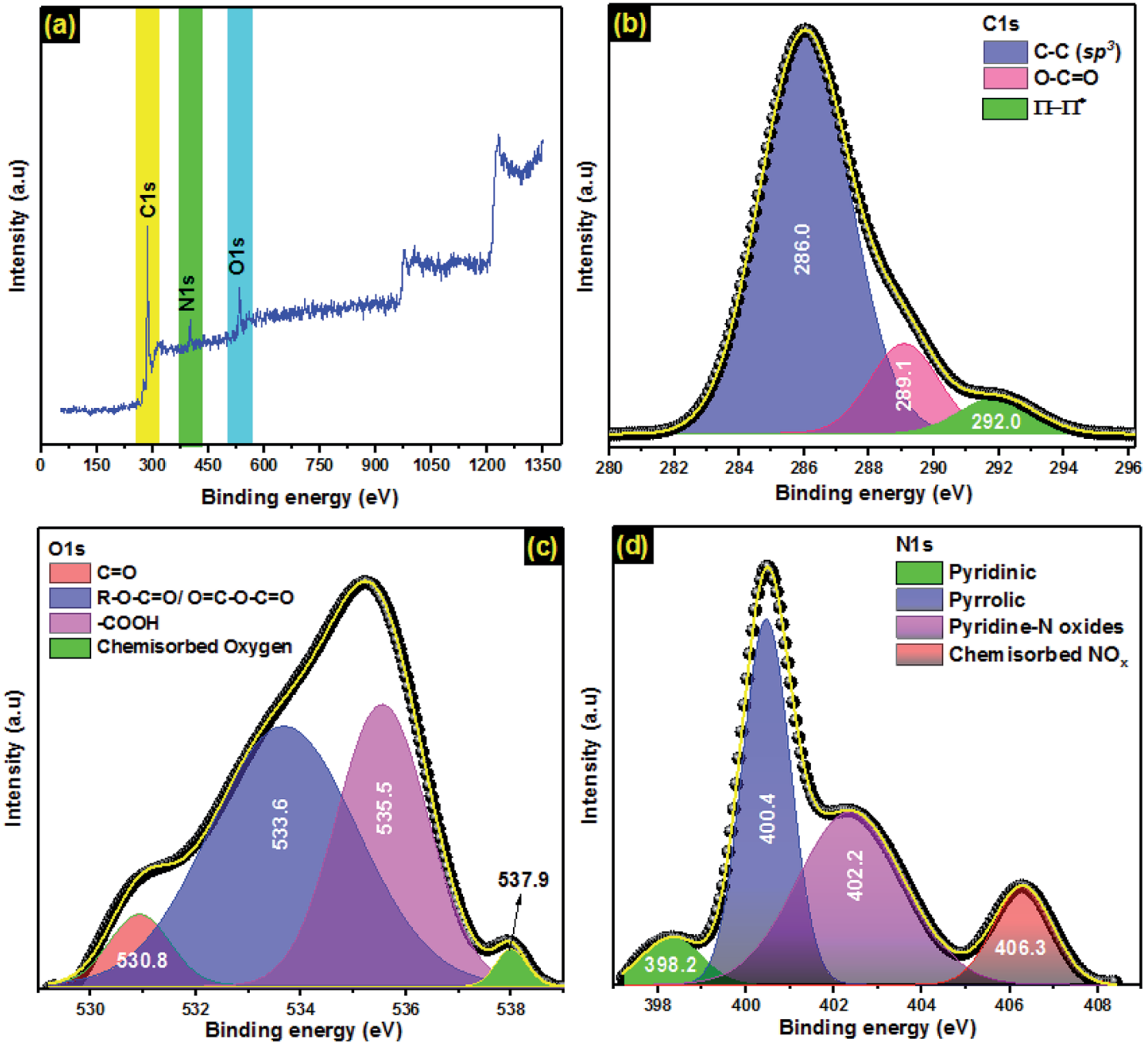

Fig. 1 (a) XPS survey scans; (b) high-resolution fitted XPS C 1s; (c) high-resolution fitted XPS O 1s, (d) high-resolution fitted XPS N 1s. 

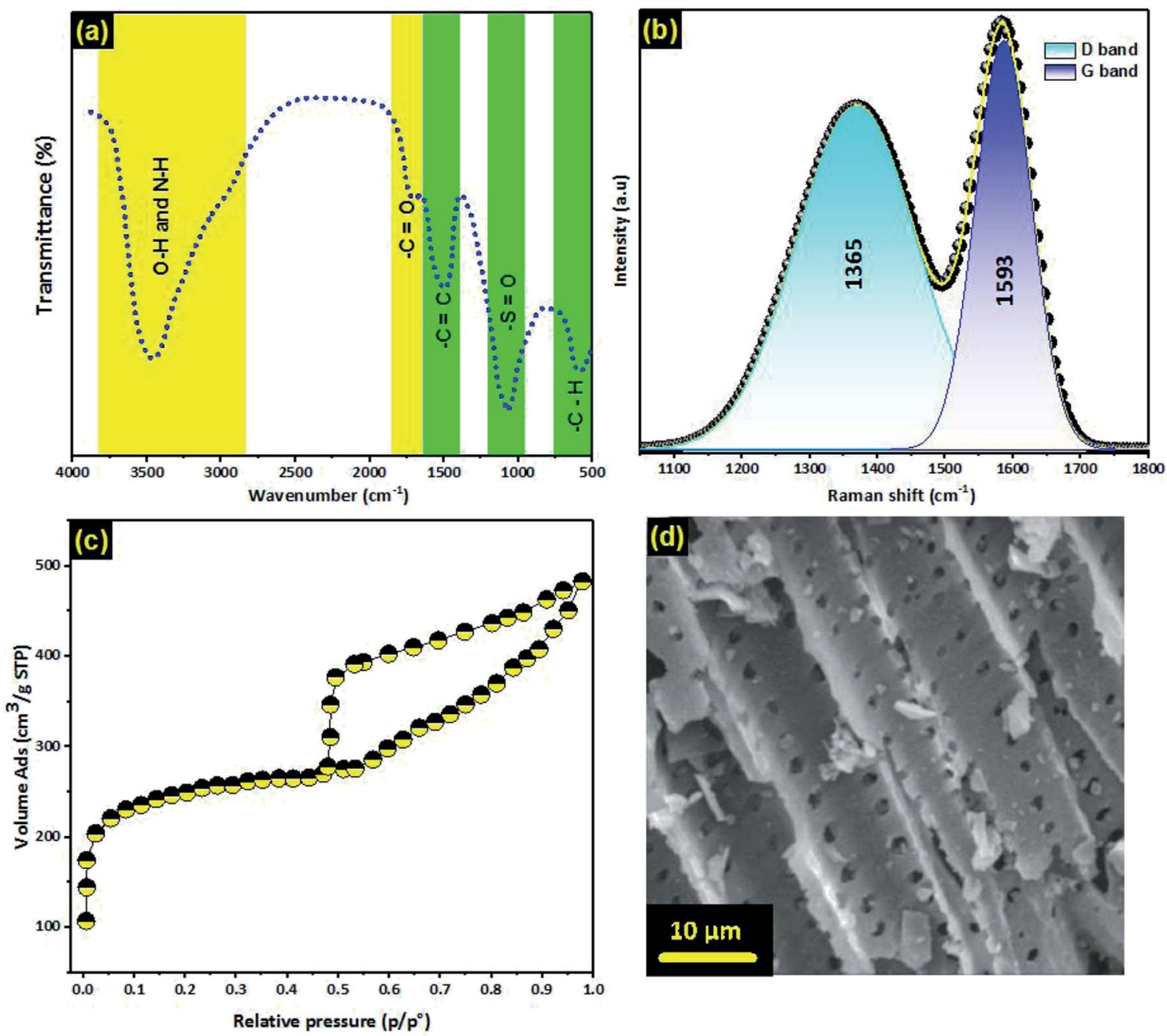

Fig. 2 (a) FTIR spectra; (b) Raman spectra; (c) adsorption-desorption isotherm; (d) SEM image of PCLDaNaOH.

spectrum illustrated in the figure displays two noticeable peaks. The peak located at 1365 and $1593 \mathrm{~cm}^{-1}$ analogous to $\mathrm{C}-\mathrm{C}$ graphitic lattice vibration mode with $\mathrm{A}_{1 \mathrm{~g}}$ symmetry and recognized to be characteristics of disordered graphite structure defect D-band. However, the G-band ( $\mathrm{sp}^{2}$-hybridized carbon) relates to an ideal graphitic lattice vibrational mode with $\mathrm{E}_{2 \mathrm{G}}$ symmetry. ${ }^{62}$ The calculated ID/IG ratio of PCLD@NaOH from the $\mathrm{D}$ and $\mathrm{G}$ bands intensities is 0.86 showing a low degree of graphitic crystalline structure.
3.1.4. $\mathbf{N}_{2}$-physisorption and SEM analysis. The nitrogen adsorption-desorption isotherm of PCLD@NaOH is shown in Fig. 2c. The prepared PCLD@NaOH displays a combined type I and IV adsorption-desorption isotherm. The sharp increase of the adsorption volume at a very low relative pressure $\left(p / p^{0}<0.1\right)$ designates the development of micropores. The incessant large increase of the $\mathrm{N}_{2}$ adsorption volume with the increase of relative pressure until $p / p^{0}=0.99$ and the typical hysteresis loop at central to high relative pressures disclose the presence of

Table 2 Concentrations $\left(\mathrm{mmol} \mathrm{g}^{-1}\right)$ of functions groups and surface textural properties of PCLD@NaOH

\begin{tabular}{|c|c|c|c|c|c|}
\hline \multirow[t]{2}{*}{ PCLD@NaOH } & 2.06 & 0.67 & 0.86 & 3.59 & 2.15 \\
\hline & $\begin{array}{l}\text { BET surface area } \\
\left(\mathrm{m}^{2} \mathrm{~g}^{-1}\right)\end{array}$ & $\begin{array}{l}\text { Micropore area } \\
\left(\mathrm{m}^{2} \mathrm{~g}^{-1}\right)\end{array}$ & $\begin{array}{l}\text { Total pore volume } \\
\left(\mathrm{cm}^{3} \mathrm{~g}^{-1}\right)\end{array}$ & $\begin{array}{l}\text { External surface } \\
\text { area }\left(\mathrm{m}^{2} \mathrm{~g}^{-1}\right)\end{array}$ & $\begin{array}{l}\text { Average pore } \\
\text { diameter (nm) }\end{array}$ \\
\hline
\end{tabular}


mesopores. The pore characteristics of the PCLD@NaOH are listed in Table 2 . The BET surface area, pore volume and average pore diameter of PCLD@NaOH are $799 \mathrm{~m}^{2} \mathrm{~g}^{-1}, 1.12 \mathrm{~cm}^{3} \mathrm{~g}^{-1}$, and $1.98 \mathrm{~nm}$, respectively.

The SEM image of PCLD@NaOH (Fig. 2d) looked like the sieve with a well-developed and homogenous micro-pores structure. These micro-pores structures occurred from $\mathrm{NaOH}$ burn out by pyrolysis of LD algae at $600{ }^{\circ} \mathrm{C}$. The well-developed structure of PCLD@NaOH might be advantageous for the adsorption of ketoprofen and aspirin molecules.

\subsection{Effect of adsorbent mass and initial pH effect}

The effect of PCLD@NaOH mass on ketoprofen and aspirin adsorption (Fig. 3a) shows that the removal efficiency of ketoprofen and aspirin by PCLD@NaOH increased by increased the mass of PCLD@NaOH from $5 \mathrm{mg}$ to $20 \mathrm{mg}$. Increasing the quantity of PCLD@NaOH offers more open binding sites. The highest removal efficiency was obtained with $20 \mathrm{mg}$ of PCLD@NaOH which is corresponding to 92\% and 95\% removal of ketoprofen and aspirin, respectively. Henceforth, the mass of PCLD@NaOH used for next experiments is $20 \mathrm{mg}$.

In order to explain the influence of $\mathrm{pH}$ solution on adsorption efficiency, the value of $\mathrm{pH}_{\mathrm{ZPC}}$ is an important parameter that decides the nature of charges on the surface of an adsorbent. ${ }^{63}$ PCLD@NaOH has a $\mathrm{pH}_{\mathrm{ZPC}}$ of 6.7, as revealed in Fig. 3c. Consequently, the surface of PCLD@NaOH has positive charges at $\mathrm{pH}<6.7$ and negative charges at $\mathrm{pH}>6.7$. Fig. $3 \mathrm{~b}$ displays the relation between PCLD@NaOH performance and solution $\mathrm{pH}$ (2.0-12.0) for the aspirin and ketoprofen molecules with an initial concentration of $150 \mathrm{mg} \mathrm{\textrm {L } ^ { - 1 }}$. The original $\mathrm{pH}$ of both molecules solution was around 3.20. The removal of aspirin and ketoprofen was mostly higher in acidic solutions than in the basic region. The high aspirin uptake of $95 \%$ was reported at $\mathrm{pH}$ 3.4 relative to 10.84 at $\mathrm{pH}$ 12.0. Similarly, the high ketoprofen removal (92\%) was observed at $\mathrm{pH} 3.4$ and $27.16 \%$ at $\mathrm{pH} 12.0$. During the adsorption on PCLD@NaOH at pH 3, the aspirin and ketoprofen molecules are in their neutral forms. ${ }^{\mathbf{1 4 , 2 3 , 6 4}}$ They can form strong $\mathrm{H}$-bonds with oxygen-containing surface functional groups present in PCLD@NaOH and be not repelled by the surface positive charge. ${ }^{65}$ Accordingly, they presented their highest aspirin adsorption at $\mathrm{pH} 3.4$, which was close to the original $\mathrm{pH}$ of the aspirin solution. As the solution $\mathrm{pH}$ increased from 3.4 to 12.0, aspirin and ketoprofen were progressively transformed to its carboxylate conjugate bases, which were repelled from the increasingly negatively charged PCLD@NaOH surfaces. For that reason, the removal of aspirin and ketoprofen

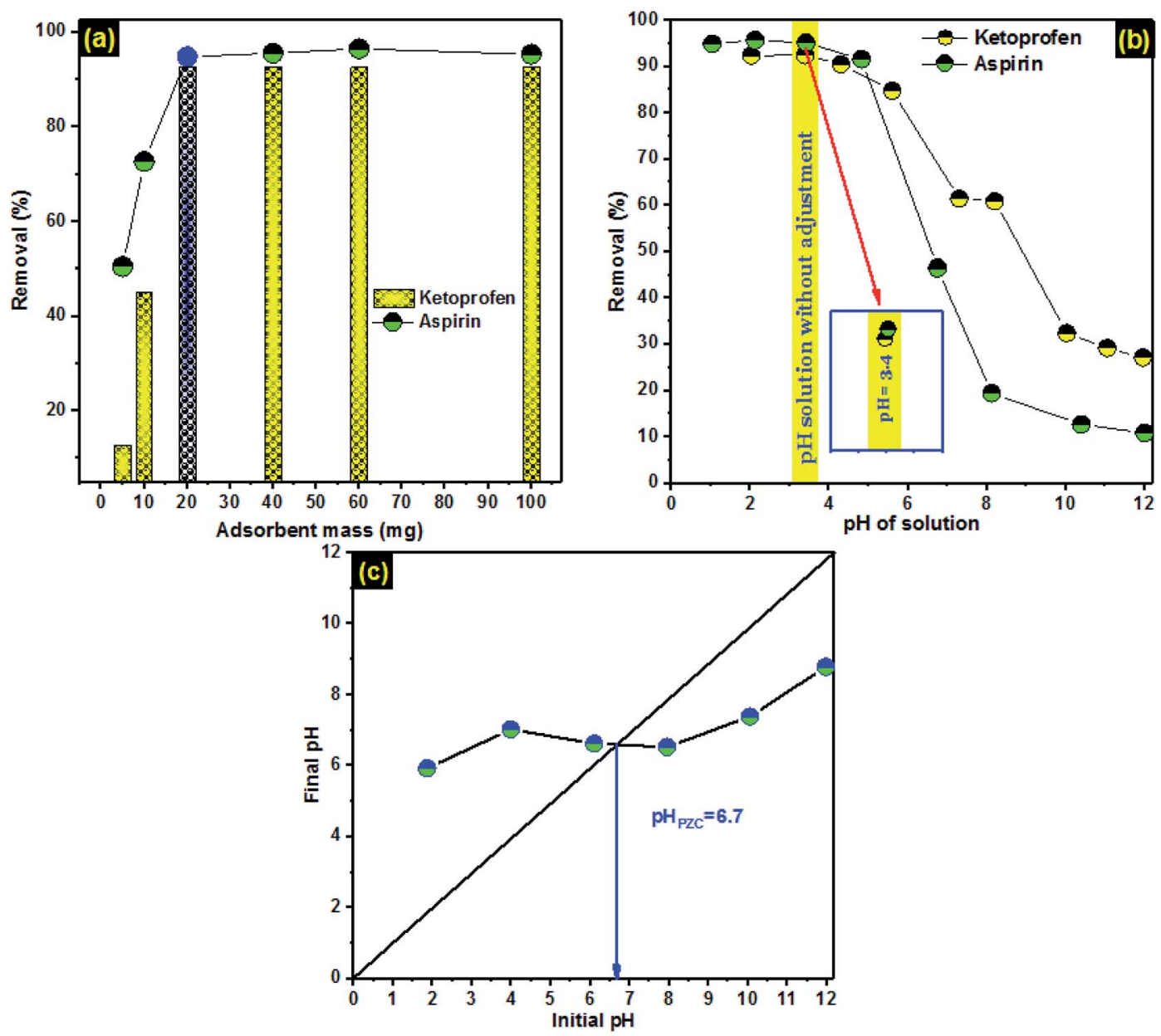

Fig. 3 (a) Effect of adsorbent mass; (b) effect of $\mathrm{pH}$ solution (c) point of zero charges $\mathrm{pH}_{\mathrm{PzC}}$. 

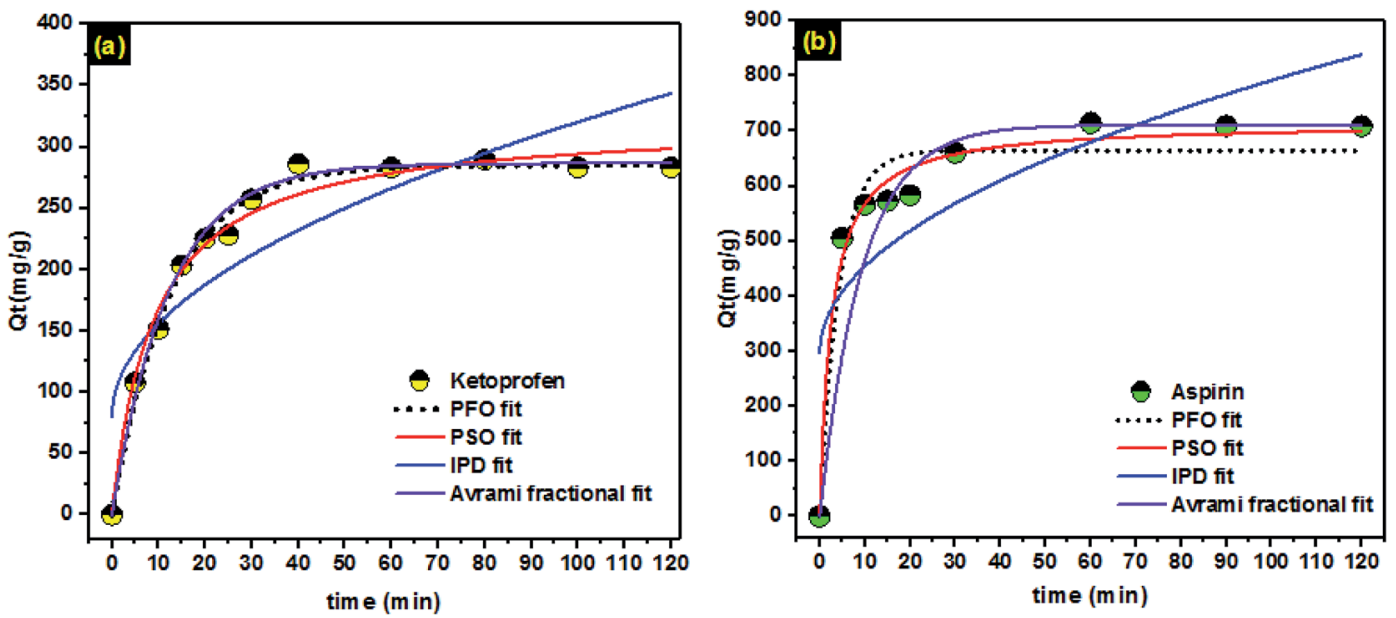

Fig. 4 Nonlinear kinetic model: pseudo-first-order (PFO), pseudo-second-order (PSO), intraparticle diffusion (IPD), and Avrami fractional model of (a) aspirin (b) ketoprofen.

in molecular form was favorable to the PCLD@NaOH, while the removal of the anionic state of aspirin and ketoprofen were unfavorable. Duplicate remarks were stated in the literature for the adsorption of aspirin and ketoprofen. ${ }^{\mathbf{1 4 , 2 3 , 2 4}}$

\subsection{Adsorption kinetic}

Kinetic studies give interesting information about the entire adsorption process counting operation control and evaluation of the adsorbent efficiencies. ${ }^{45,66,67}$ Herein, the effect of contact time on adsorption of ketoprofen and aspirin by PCLD@NaOH was studied using nonlinear pseudo-first order, pseudo-second order, and Avrami fractional-order kinetic models. The kinetic curves and fitting parameters of the models are presented in Fig. 4 and Table 3, respectively. The accuracy of each model is clarified using the values of the standard deviation of residues (SD). Lower SD value designates smaller disparity between theoretical and experimental $Q$ values. To compare the appropriateness of each model, the SD of each model was divided by the SD of the minimum value to obtain the SD ratio. Avrami fractional-order model has the lowest SD ratio values compared to pseudo-first order and pseudo-second-order models. Consequently, the Avrami fractional-order model describes well the adsorption kinetics of ketoprofen and aspirin onto PCLD@NaOH. The kinetic rate constant of the kinetic models has dissimilar units; it is hard to compare the rates of the kinetics of adsorption of ketoprofen and aspirin. ${ }^{68}$ The half-life $\left(t_{1 / 2}\right)$, which is the time to reach $50 \%$ of adsorption capacity at the equilibrium $\left(Q_{\mathrm{e}}\right)$, was calculated by interpolation in the fitting kinetic curve. It is observed that $t_{1 / 2}$ of aspirin $(6.486 \mathrm{~min})$ was lower than $t_{1 / 2}$ of ketoprofen $(8.424 \mathrm{~min})$. Therefore, the time for attaining the equilibrium was so fast in the case of aspirin compared to ketoprofen.

In order to define the time needed to accomplish the equilibrium, an interpolation was made on the Avrami fractionalorder kinetic model plot for ketoprofen and aspirin adsorption. In this calculation, the value of $Q_{t}$ that was $95 \%$ of the maximum value of experimental $Q_{\mathrm{e}}$ was used. ${ }^{69}$ This time is defined as $t_{0.95}$. The $t_{0.95}$ was calculated just for the Avrami fractional-order kinetic model because it was the best kinetic model for fitting the ketoprofen and aspirin experimental data in this work. Examining the values stated in Table 3, the maximum $t_{0.95}$ is $36.756 \mathrm{~min}$ and $28.228 \mathrm{~min}$ for ketoprofen and aspirin, respectively. Rapid adsorption of aspirin onto PCLD@NaOH designated high affinity between the aspirin

Table 3 Kinetic model parameters for ketoprofen and aspirin adsorption

\begin{tabular}{|c|c|c|}
\hline & Ketoprofen & Aspirin \\
\hline$Q_{e, \exp }\left(m g g^{-1}\right)$ & 286 & 714 \\
\hline \multicolumn{3}{|l|}{ Pseudo-first-order } \\
\hline$Q_{\mathrm{e}, \mathrm{cal}}\left(\mathrm{mg} \mathrm{g}^{-1}\right)$ & 286.62 & 711.19 \\
\hline$K_{1}\left(\min ^{-1}\right)$ & 0.082 & 0.106 \\
\hline$t_{1 / 2}(\min )$ & 8.453 & 6.539 \\
\hline$R^{2}$ & 0.999 & 0.999 \\
\hline $\mathrm{SD}\left(\mathrm{mg} \mathrm{g}^{-1}\right)$ & 2.926 & 2.990 \\
\hline \multicolumn{3}{|l|}{ Pseudo-second-order } \\
\hline$Q_{\mathrm{e}, \mathrm{cal}}\left(\mathrm{mg} \mathrm{g}^{-1}\right)$ & 305.14 & 736.16 \\
\hline$K_{2}\left(\mathrm{~g} \mathrm{mg}^{-1} \min ^{-1}\right)$ & 0.0005 & 0.0004 \\
\hline$t_{1 / 2}(\min )$ & 6.554 & 3.396 \\
\hline$R^{2}$ & 0.998 & 0.998 \\
\hline $\mathrm{SD}\left(\mathrm{mg} \mathrm{g}^{-1}\right)$ & 6.997 & 8.645 \\
\hline \multicolumn{3}{|l|}{ Avrami-fractional-order } \\
\hline$K_{\mathrm{AV}}\left(\min ^{-1}\right)$ & 0.177 & 1.023 \\
\hline$Q_{\mathrm{e}, \mathrm{cal}}\left(\mathrm{mg} \mathrm{g}^{-1}\right)$ & 286.62 & 711.19 \\
\hline$n_{\mathrm{AV}}$ & 0.463 & 0.104 \\
\hline$t_{1 / 2}(\min )$ & 8.424 & 6.486 \\
\hline$t_{0.95}(\mathrm{~min})$ & 36.756 & 28.228 \\
\hline$R^{2}$ & 0.999 & 0.999 \\
\hline $\mathrm{SD}\left(\mathrm{mg} \mathrm{g}^{-1}\right)$ & 2.056 & 2.708 \\
\hline \multicolumn{3}{|c|}{ Intraparticle diffusion model } \\
\hline$K_{\text {ip }}\left(\mathrm{mg} \mathrm{g}^{-1} \min ^{-1 / 2}\right)$ & 24.02 & 49.34 \\
\hline$C\left(\mathrm{mg} \mathrm{g}^{-1}\right)$ & 80.01 & 298.09 \\
\hline$R^{2}$ & 0.744 & 0.616 \\
\hline
\end{tabular}


molecules and the surfaces of the PCLD@NaOH compared to ketoprofen. For subsequent experiments, the contact time was fixed at $60 \mathrm{~min}$ for both pollutants molecules.

Moreover, Fig. 4 displays the curve-fitting plots of IPD model for ketoprofen and aspirin adsorption. The values of the intercept C (ketoprofen: $80.01 \mathrm{mg} \mathrm{g}^{-1}$; aspirin: $298.09 \mathrm{mg} \mathrm{g}^{-1}$ ), give an idea about the boundary layer thickness: the larger intercept, the greater is the boundary layer effect in adsorption by PCLD@NaOH. Meanwhile, the plots do not pass over the origin, this indicates that there lies some degree of boundary layer control and the IPD is not the solitary rate-controlling step, but also additional processes may control the rate of adsorption. ${ }^{70}$ Henceforth, the IPD model is not appropriate for describing the ketoprofen and aspirin removal from water onto PCLD@NaOH. It can be concluding that the PSO model described well the kinetics data of ketoprofen and aspirin instead of PFO and IPD models. The best fitting of analysis kinetics data by PSO model for ketoprofen and aspirin were also observed for ketoprofen onto MIL-101(Cr)/natural polymer composite beads ${ }^{23}$ and aspirin on biochar. ${ }^{14}$

\subsection{Adsorption isotherms}

Fitting adsorption isotherms data using the non-linear equation of Langmuir, Freundlich, and Liu models (Table 1) is a useful approach to describe the relationship between the ketoprofen and aspirin concentration in the solution (liquid phase) and the PCLD@NaOH (solid phase) at a constant temperature and design adsorption systems. The adsorption isotherm of ketoprofen and aspirin onto PCLD@NaOH at different temperature are illustrated in Fig. 5, and the corresponding parameters of aspirin and ketoprofen adsorption are presented in Table 4. The SD values of the Langmuir model range from 16 to 21 (ketoprofen) and 21 to 33 (aspirin). The SD ratios of Freundlich model range from 29 to 36 (ketoprofen) and 40 to 83 (aspirin). Liu isotherm was the most appropriate model for the adsorption of ketoprofen and aspirin. The Liu model showed the lowest SD and highest $R^{2}$ values. This result means that the $Q$ values obtained experimentally are very close to those $Q$ values calculated by the isotherm model. ${ }^{45,71,72}$ Furthermore, the ketoprofen and aspirin adsorption was significantly influenced by the operating temperatures. The amount of aspirin and ketoprofen adsorbed decreased with increasing temperature, indicating that the adsorption of ketoprofen and aspirin is of exothermic nature. These results show that the decrease of adsorption at a high temperature can be attributed to the greater tendency of ketoprofen and aspirin molecules to form hydrophobic bonds in an aqueous medium, thus hindering their hydrophobic interactions with the adsorbent surface. ${ }^{73}$ On the other hand, the decreased adsorption at equilibrium is owing to decreased surface activity at higher temperatures. ${ }^{74}$

The $Q_{\max }$ values obtained by Liu model at $25{ }^{\circ} \mathrm{C}, 40{ }^{\circ} \mathrm{C}$, and $50{ }^{\circ} \mathrm{C}$ were as follows: $443.45 \mathrm{mg} \mathrm{g}^{-1}>315.81 \mathrm{mg} \mathrm{g}^{-1}>$ $232.51 \mathrm{mg} \mathrm{g}^{-1}$ for ketoprofen and $970.88 \mathrm{mg} \mathrm{g}^{-1}>662.90 \mathrm{mg}$ $\mathrm{g}^{-1}>391.59 \mathrm{mg} \mathrm{g}^{-1}$ for aspirin.

By comparing our results with other previously reported adsorbents (Table 5), it could be seen that the adsorption

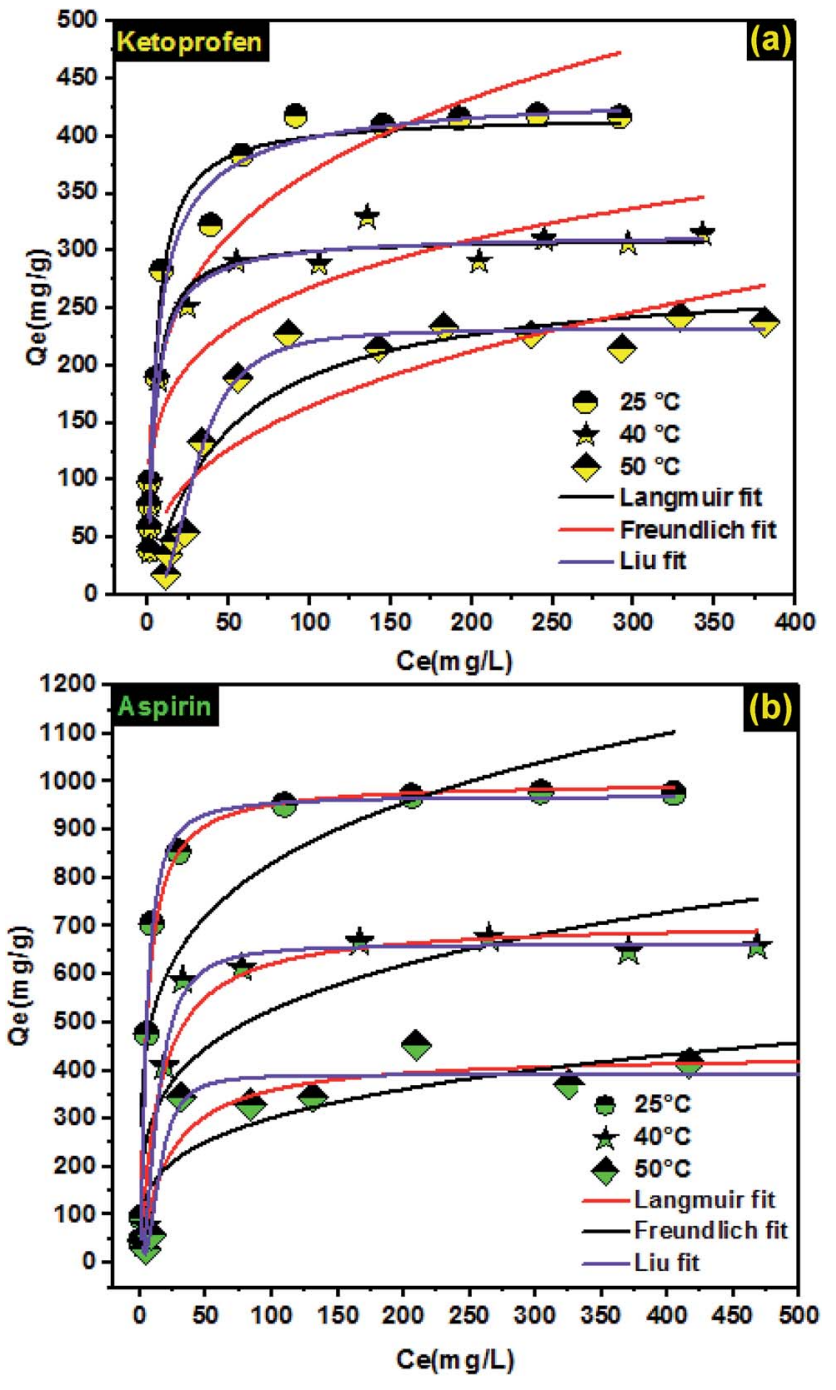

Fig. 5 Nonlinear isotherm models: Langmuir, Freundlich, and Liu of (a) ketoprofen (b) aspirin.

capacity of PCLD@NaOH was higher for both ketoprofen and aspirin molecules, suggesting that the prepared PCLD@NaOH might be a potential candidate for removal of pharmaceutical molecules from aqueous solution.

\subsection{Thermodynamic behavior}

The behavior of adsorption (i.e., physical or chemical) can be sensibly understood over the study of adsorption thermodynamics. The thermodynamic parameters $\left(\Delta G^{\circ}, \Delta H^{\circ}\right.$, and $\left.\Delta S^{\circ}\right)$ can be computed by the Van't Hoff approach. ${ }^{51,83}$ In this section, we applied Van't Hoff equation and Gibbs energy equations (Table 1) to calculate the thermodynamic parameters of the ketoprofen and aspirin adsorption onto PCLD@NaOH (Fig. 6a). From Table 6 , the negative $\Delta G^{\circ}$ values at all examined temperatures for ketoprofen and aspirin specify that the adsorption phenomenon happened spontaneously. Moreover, the negative $\left(-\Delta S^{\circ}\right)$ values reveal that the organization of ketoprofen and aspirin molecules at the solid/solution interface through the adsorption process onto PCLD@NaOH becomes less random 
Table 4 Isotherm model parameters for the adsorption of ketoprofen and aspirin at different temperatures

\begin{tabular}{|c|c|c|c|c|c|c|}
\hline \multirow[b]{2}{*}{ Temperature } & \multicolumn{3}{|c|}{ Ketoprofen } & \multicolumn{3}{|l|}{ Aspirin } \\
\hline & $25^{\circ} \mathrm{C}$ & $40{ }^{\circ} \mathrm{C}$ & $50^{\circ} \mathrm{C}$ & $25^{\circ} \mathrm{C}$ & $40^{\circ} \mathrm{C}$ & $50{ }^{\circ} \mathrm{C}$ \\
\hline$Q_{\max }\left(\mathrm{mg} \mathrm{g}^{-1}\right)$ & 418.46 & 311.67 & 280.87 & 1000.29 & 711.36 & 435.52 \\
\hline$K_{\mathrm{L}}\left(\mathrm{L} \mathrm{mg}^{-1}\right)$ & 0.212 & 0.246 & 0.021 & 0.199 & 0.069 & 0.047 \\
\hline$R^{2}$ & 0.975 & 0.979 & 0.910 & 0.989 & 0.955 & 0.919 \\
\hline \multicolumn{7}{|l|}{ Freundlich } \\
\hline$K_{\mathrm{F}}\left(\mathrm{mg} \mathrm{g}^{-1}\right)\left(\mathrm{L} \mathrm{mg}^{-1}\right)^{1 / n}$ & 125.97 & 101.95 & 29.88 & 326.13 & 177.38 & 91.70 \\
\hline$n$ & 4.29 & 4.76 & 2.70 & 4.92 & 4.23 & 3.86 \\
\hline$R^{2}$ & 0.903 & 0.871 & 0.787 & 0.804 & 0.745 & 0.737 \\
\hline $\mathrm{SD}\left(\mathrm{mg} \mathrm{g}^{-1}\right)$ & 29.414 & 36.736 & 32.009 & 83.505 & 65.547 & 40.333 \\
\hline$R^{2}$ & 0.988 & 0.983 & 0.984 & 0.997 & 0.994 & 0.945 \\
\hline $\mathrm{SD}\left(\mathrm{mg} \mathrm{g}^{-1}\right)$ & 11.464 & 6.613 & 5.229 & 11.135 & 10.547 & 12.045 \\
\hline
\end{tabular}

when the temperature increases. A negative value of $\Delta H^{\circ}$ advises that the adsorption process happened exothermically. An exothermic process is clearly recognized to physical adsorption (physisorption) with the presence of relatively weak interactions (i.e., van der Waals force); consequently, the amount of ketoprofen and aspirin adsorbed tends to desorb easily when temperature increases (exothermic). ${ }^{84}$

\subsection{Regeneration of adsorbent}

To envisage the regeneration of PCLD@NaOH, ethanol was used to desorb aspirin and ketoprofen from PCLD@NaOH. ${ }^{\mathbf{8 5 , 8 6}}$ The reusability of the PCLD@NaOH was determined using 5 cycles of adsorption-regeneration. A sample of $20 \mathrm{mg}$ of PCLD@NaOH was shaken with $100 \mathrm{~mL}$ solution of aspirin and ketoprofen $\left(150 \mathrm{mg} \mathrm{L}^{-1}\right)$ for $2 \mathrm{~h}$ at room temperature. Then, the PCLD@NaOH was filtered, washed and then dried at $100{ }^{\circ} \mathrm{C}$. After each adsorption, the regeneration process was repeated. Fig. $6 \mathrm{~b}$ demonstrates that the adsorption efficacy of PCLD@NaOH after 5 adsorption-regeneration cycles is $\sim 90.6 \%$ for aspirin and $90.2 \%$ for ketoprofen. Correspondingly, the removal rate of aspirin and ketoprofen was diminished by $4.6 \%$ and $1.95 \%$ after 5 cycles, respectively. These results validate that PCLD@NaOH reveals outstanding stability and can be used many times without a significant loss in the adsorption proficiency of aspirin and ketoprofen.

\subsection{Proposed mechanism}

To elucidate the adsorption mechanism of ketoprofen and aspirin on PCLD@NaOH, FTIR spectroscopy was used to study the behavior of PCLD@NaOH before and after adsorption (Fig. 7). Mostly, the possible mechanisms for the adsorption of organic pollutants on carbon materials are an electrostatic attraction, hydrogen bond formation, $n-\pi$ interaction, $\pi-\pi$ interaction, and pores filling. ${ }^{85,87,88}$ The FTIR pattern of ketoprofen loaded PCLD@NaOH and aspirin loaded PCLD@NaOH shows that the peaks around 3451, 1732, and $1492 \mathrm{~cm}^{-1}$ are slightly shifted from their initial location to 3367,1741 , and $1476 \mathrm{~cm}^{-1}$, respectively (Fig. 7). Whereas the peak situated at

Table 5 Adsorption capacities of ketoprofen and aspirin on PCLD@NaOH compared to the literature data

\begin{tabular}{|c|c|c|c|}
\hline & Adsorbent & $Q_{\max }\left(\mathrm{mg} \mathrm{g}^{-1}\right)$ & Reference \\
\hline \multirow[t]{5}{*}{ Ketoprofen } & PCLD@NaOH & 443.45 & This work \\
\hline & Molecularly imprinted polymer (MIP) & 8.7 & 75 \\
\hline & MIL-101-(OH $)_{3}$ & 80 & 77 \\
\hline & Graphene oxide & 63 & 78 \\
\hline & MIL-101(Cr)/CS & 156 & 23 \\
\hline & AC derived from rice hull $\left(\mathrm{H}_{3} \mathrm{PO}_{4} / 500{ }^{\circ} \mathrm{C}\right)$ & 178.89 & 80 \\
\hline & $\mathrm{Fe} / \mathrm{N}-\mathrm{CNT} / \beta$-cyclodextrin nanocomposites & 71.9 & 81 \\
\hline & Graphene nanoplatelets & 12.98 & 82 \\
\hline
\end{tabular}



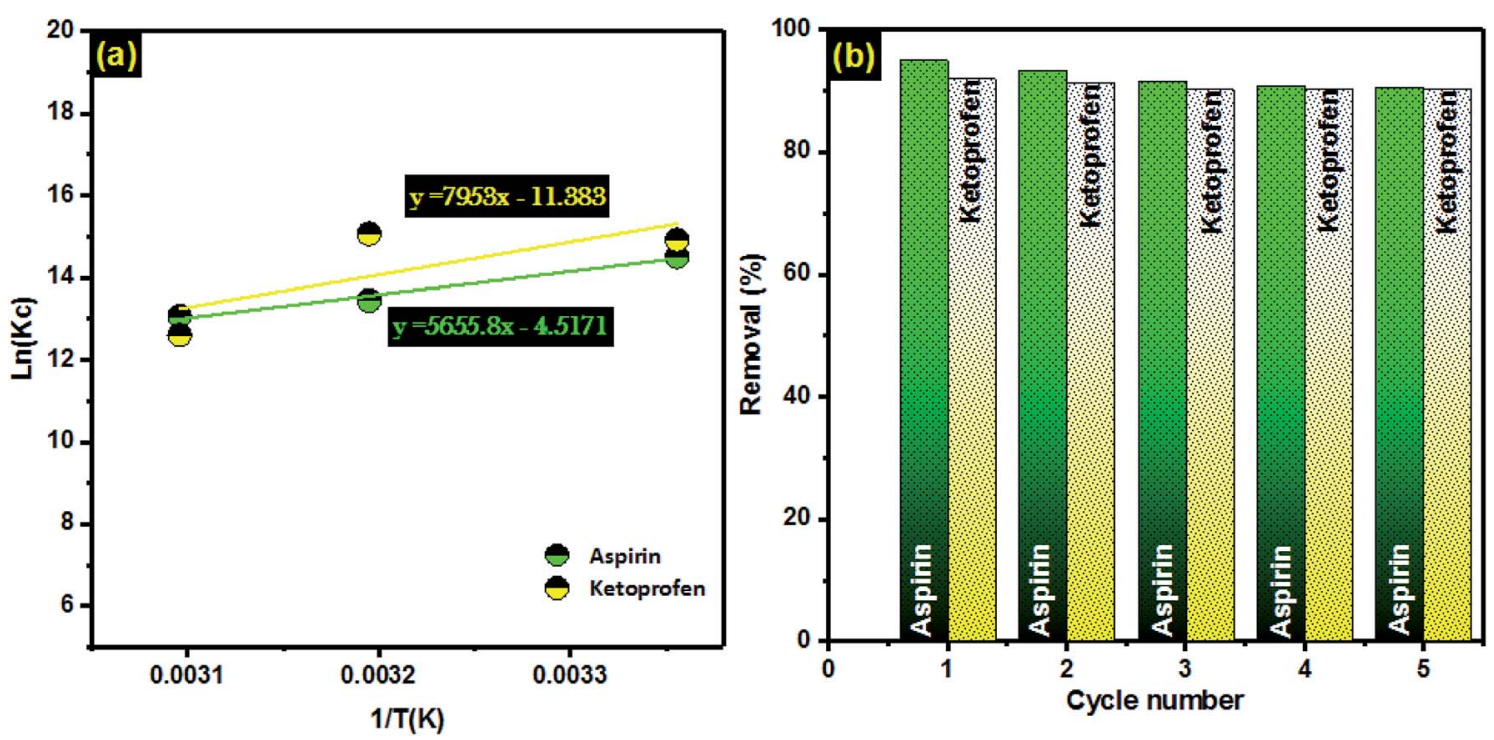

Fig. 6 (a) Linear dependence of $\ln K_{\mathrm{c}}$ on $1 / T$ based on the adsorption thermodynamics; (b) regeneration and recyclability of PCLD @NaOH over five cycles of use.

$3354 \mathrm{~cm}^{-1}$ is linked to $-\mathrm{OH}$ groups and the peak detected at $1732 \mathrm{~cm}^{-1}$ is analogous to $\mathrm{C}=\mathrm{O}$ and at $1492 \mathrm{~cm}^{-1}$ is ascribed to $\mathrm{C}=\mathrm{C}$ of the aromatic rings. The move of these peaks can be understood by the formation of hydrogen bonds between hydroxyl groups present in ketoprofen and aspirin molecules and PCLD@NaOH, and hydrogen bonds between -OH present in PCLD@NaOH with $-\mathrm{C}=\mathrm{O}$ present in the ketoprofen and aspirin molecules. ${ }^{87-89}$ Finally, the shift of $\mathrm{C}=\mathrm{C}$ is explained by the $\pi-\pi$ interaction between ketoprofen and aspirin on PCLD@NaOH. In Fig. 8, the schematic representation of the $\pi-$ $\pi$ interaction and hydrogen bonding between ketoprofen and aspirin with PCLD@NaOH is presented.

\subsection{Theoretical investigation of ketoprofen and aspirin reactivity using DFT approach}

The electronic molecular descriptors of ketoprofen and aspirin molecules and their values calculated are exposed in Table 7. Fig. 9 and 10 shows the optimized geometries, the electrostatic surface potential (ESP), HOMO, and LUMO orbitals of ketoprofen and aspirin molecules. Molecular orbitals play an essential role in the understanding of the chemical reactivity at the atomic level. Furthermore, they are important descriptors for the explanation of various chemical reactions. The $E_{\text {Номо }}$ and $E_{\text {LUMO }}$ energies values calculated for the studied pharmaceutical pollutants are aspirin $\left(E_{\mathrm{HOMO}}=-7.103 \mathrm{eV} ; E_{\mathrm{L}}=-1.568\right.$ $\mathrm{eV})$ and ketoprofen $\left(E_{\mathrm{H}}=-6.913 \mathrm{eV} ; E_{\mathrm{L}}=-0.594 \mathrm{eV}\right)$. The values of the HOMO-LUMO energy gap $(\Delta E)$ calculated for tested molecules are aspirin $(\Delta E=5.5351 \mathrm{eV})$, and ketoprofen $(\Delta E=6.3191 \mathrm{eV})$. The results indicate that aspirin is more reactive because of the low value of the energy gap $(\Delta E) \cdot{ }^{\mathbf{9}}$ The values of electrophilicity index $(\omega)$ for aspirin $(\omega=9.400 \mathrm{eV})$ is higher than ketoprofen $(\omega=7.045 \mathrm{eV})$ which suggest that aspirin is more electrophile than ketoprofen. ${ }^{91}$ A strong and more reactive electrophile species is characterized by a high value of chemical potential $(\mu)$ and electrophilicity index $(\omega)$; the chemical potential $(\mu)$ displays the escaping tendency of electrons in a molecule. ${ }^{92}$ The values of chemical potential $(\mu)$ calculated for the studied pollutants are aspirin $(\mu=4.335 \mathrm{eV})$ and ketoprofen $(\mu=3.753 \mathrm{eV})$. Hence, the aspirin molecule has a high value of $\mu$ and $\omega$ compared to ketoprofen, accordingly, the aspirin molecule is more reactive electrophile than ketoprofen.

The stability of aspirin and ketoprofen molecules and its reactivity can be related to chemical hardness $(\eta)$. The molecule of aspirin $(\eta=2.767 \mathrm{eV})$ has a low hardness value compared to ketoprofen $(\eta=3.159 \mathrm{eV})$. Generally, a hard molecule has a large energy gap $(\Delta E)$, while soft molecule has a small energy gap (Table 7) and is more reactive. ${ }^{56,92}$

According to obtained results from calculated quantum descriptors, aspirin molecule present high reactivity, electrophilicity, and softness compared to ketoprofen molecules. These outcomes are in good agreement with adsorption

Table 6 Thermodynamic parameters for the ketoprofen and aspirin adsorption

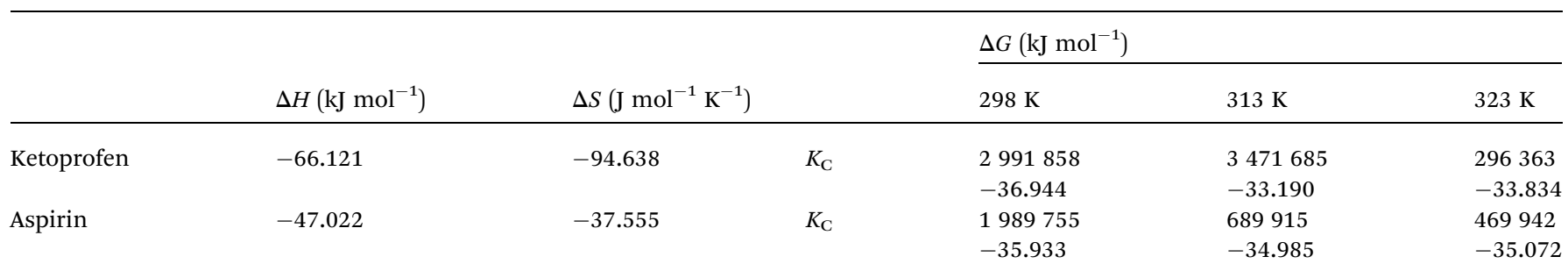




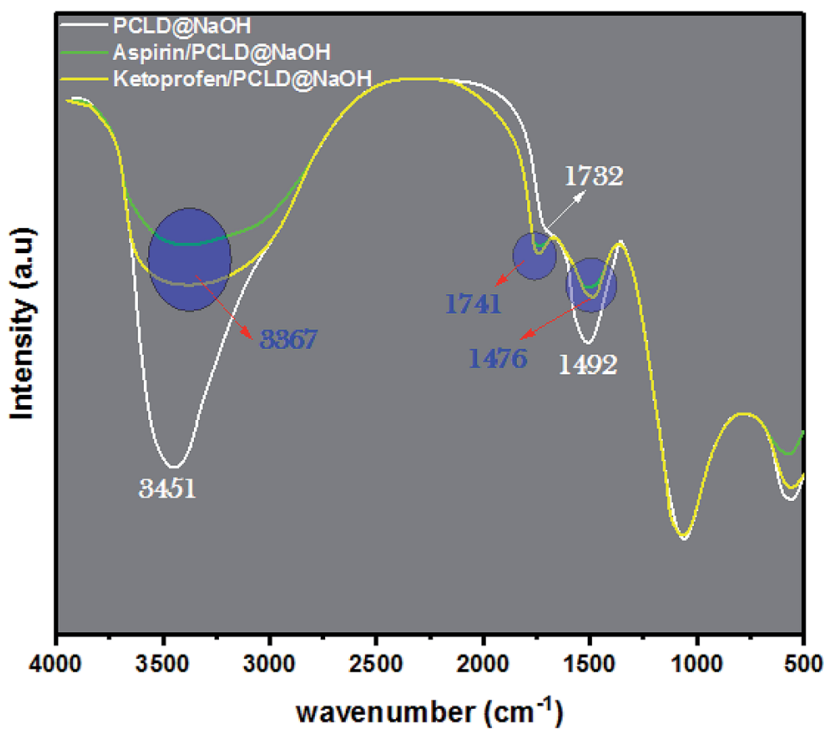

Fig. 7 FTIR analysis before and after adsorption of aspirin and ketoprofen onto PCLD@NaOH.

experiments and confirm the experimental results related to the high adsorption capacity of aspirin on PCLD@NaOH compared to ketoprofen.

\subsection{Optimization using response surface approach}

To obtain optimum operational parameters that affect ketoprofen and aspirin adsorption onto PCLD@NaOH, response surface methodology (RSM) was used to this purpose. ${ }^{26,93-96}$ In Table 8, we present the experimental levels of ketoprofen and aspirin adsorption on PCLD@NaOH, respectively. In addition, the experimental results were obtained by using the CCD matrix (Table $1 \mathrm{~S} \dagger$ ). In this work, a quadratic polynomial equation was nominated to study the influence of parameters and links the response (removal efficiency) with factors (equation below).

$$
\begin{aligned}
Y= & b_{0}+b_{1} \times X_{1}+b_{2} \times X_{2}+b_{3} \times X_{3}+b_{1-1} \times\left(X_{1} \times X_{1}\right) \\
& +b_{2-2} \times\left(X_{2} \times X_{2}\right)+b_{3-3} \times\left(X_{3} \times X_{3}\right) \\
& +b_{1-2} \times\left(X_{1} \times X_{2}\right)+b_{1-3} \times\left(X_{1} \times X_{3}\right) \\
& +b_{2-3} \times\left(X_{2} \times X_{3}\right)
\end{aligned}
$$

where $Y$ is the predicted response of ketoprofen or aspirin, $b_{0}$ is the intercept coefficient, $b_{i}$ the linear terms, $b_{i i}$ the squared terms, $b_{i j}$ the interaction terms, and $X_{1}, X_{2}, X_{3}$ and $X_{4}$ represent the coded independent variables of PCLD@NaOH mass, pH, concentration and temperature, respectively.

The established models for ketoprofen and aspirin adsorption by PCLD@NaOH were giving below using the quadratic polynomial equation.

$$
\begin{aligned}
R \%(\text { ketoprofen })= & 92.567+8.662 X_{1}-3.835 X_{2} \\
- & 3.184 X_{3}-8.250 X_{4}-12.258 X_{1-1} \\
- & 3.071 X_{2-2}-4.844 X_{4}-1.898 X_{1-3} \\
- & 1.512 X_{1-4}-4.386 X_{3-4} \\
R \%(\text { aspirin })= & 95.347-0.016 X_{2}-2.555 X_{3}-1.787 X_{4} \\
& -0.093 X_{3-3}-0.614 X_{1-2}-0.293 X_{1-4} \\
& -0.021 X_{2-4}-2.947 X_{3-4}
\end{aligned}
$$

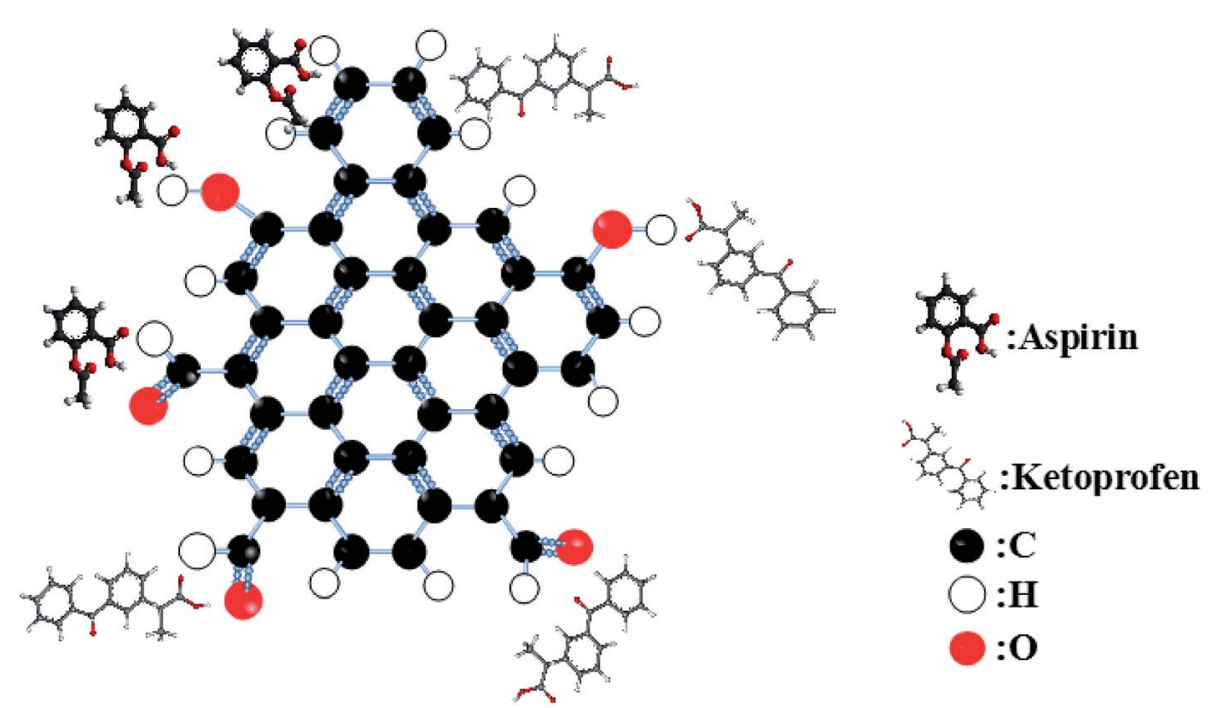

Fig. 8 Schematic representation of the proposed mechanism.

Table 7 Values of quantum chemical descriptors to basic dyes

\begin{tabular}{llllllrr}
\hline & $E_{\text {Номо }}(\mathrm{eV})$ & $E_{\mathrm{LUMO}}(\mathrm{eV})$ & $\mu(\mathrm{eV})$ & $\Delta E(\mathrm{eV})$ & $\eta(\mathrm{eV})$ & $S(\mathrm{ev})$ & $\omega(\mathrm{ev})$ \\
\hline Aspirin & -7.103 & -1.568 & 4.335 & 5.535 & 2.767 & 0.361 & 9.400 \\
Ketoprofen & -6.913 & -0.594 & 3.753 & 6.319 & 3.159 & 0.316
\end{tabular}




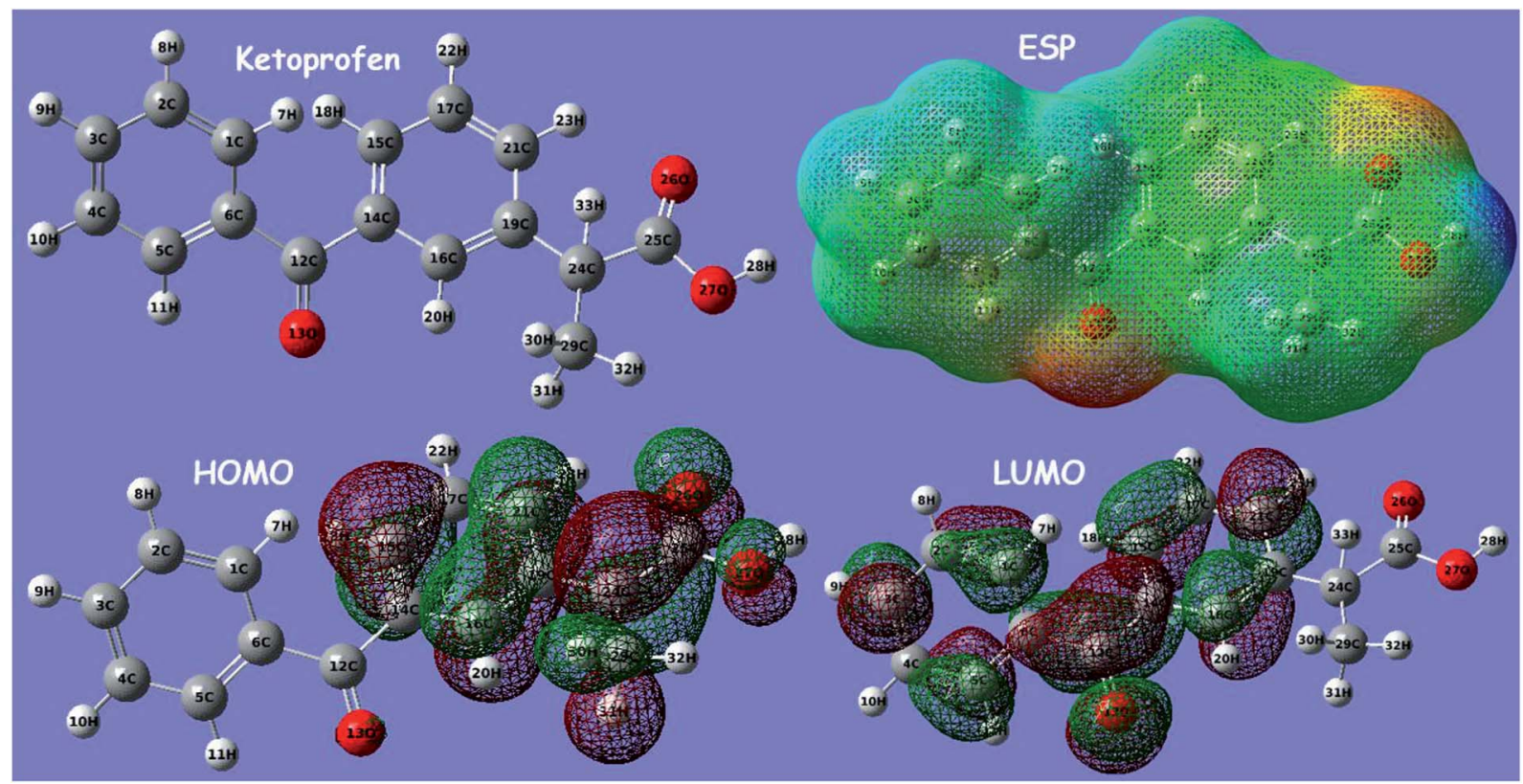

Fig. 9 Optimized geometry of ketoprofen, the electrostatic surface potential (ESP), highest occupied orbital (HOMO), and lowest molecular orbital (LUMO) structure computed using DFT method.

ANOVA analysis (Table $2 \mathrm{~S} \dagger$ ) was utilized in this work to determine the adequacy of the predicted model. ${ }^{97,98}$ Therefore, ' $P$-value' less than 0.05 infer that designed models were significant for both ketoprofen and aspirin. The correlation coefficient $\left(R^{2}\right)$ and the adjusted correlation coefficient $\left(R_{\mathrm{Adj}}{ }^{2}\right)$ were close to 0.99 for both ketoprofen and aspirin systems, showing the existence of a good correlation between data. ${ }^{26}$ Besides, the coefficients significations of ketoprofen and aspirin models were studied and their $P$-values were evaluated to confirm the significance of each one of them. From Table $2 \mathrm{~S}, \dagger$ the coefficients with $P$-values less than 0.05 are significant while the others that are below 0.05 are insignificant. In addition, Fig. $1 \mathrm{~S} \dagger$

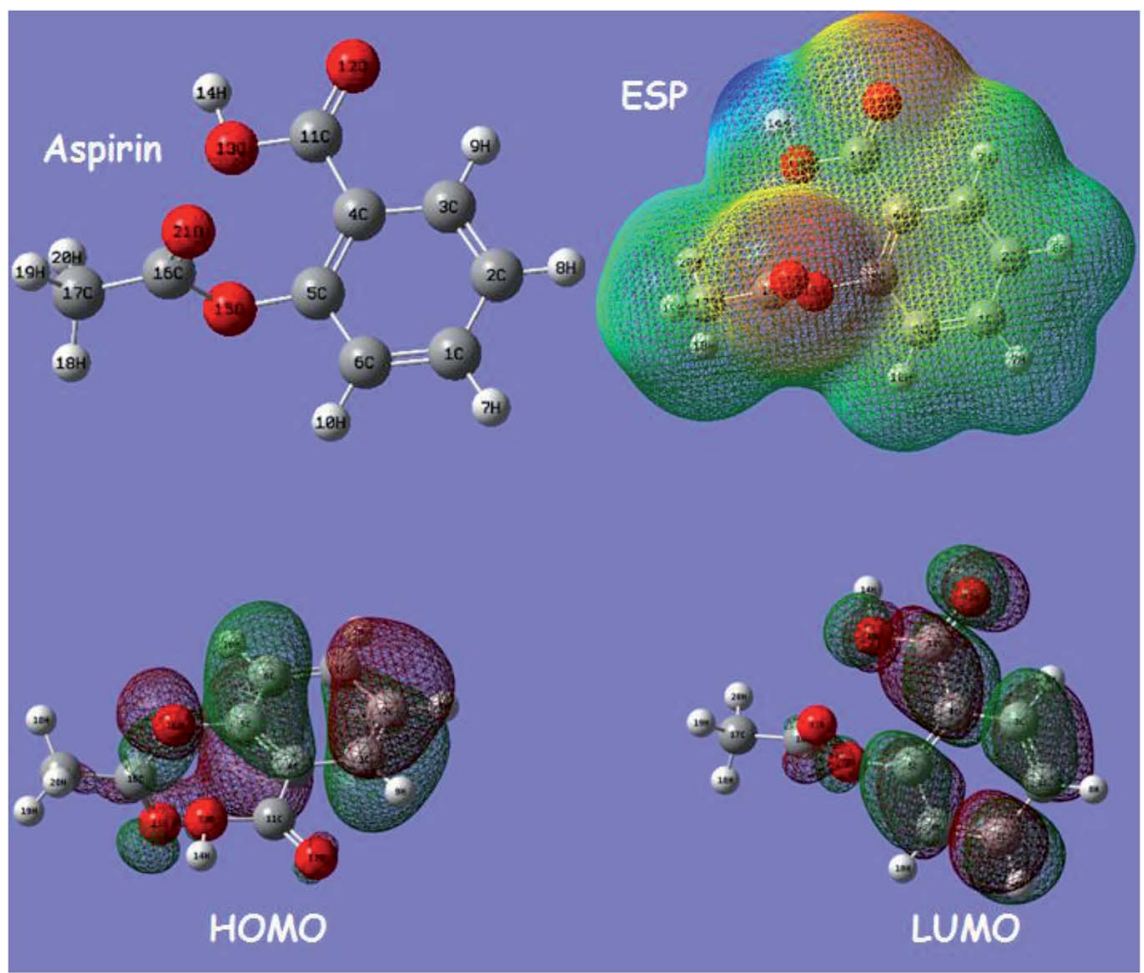

Fig. 10 Optimized geometry of aspirin, the electrostatic surface potential (ESP), highest occupied orbital (HOMO), and lowest molecular orbital (LUMO) structure computed using DFT method. 
Table 8 Experimental levels for ketoprofen and aspirin adsorption

\begin{tabular}{lllrrrr}
\hline Variable & Factor & Unit & $-2(\alpha)$ & -1 & 0 & 1 \\
\hline$X_{1}$ & Adsorbent mass & $\mathrm{mg}$ & 10.00 & 15.00 & 20.00 & 2.40 \\
$X_{2}$ & pH & & 1.40 & 2.40 & 3.40 & 4.40 \\
$X_{3}$ & Concentration & $\mathrm{mg} \mathrm{L}^{-1}$ & 50.00 & 100.00 & 150.00 & 200.00 \\
$X_{4}$ & Temperature & ${ }^{\circ} \mathrm{C}$ & 5.00 & 15.00 & 25.00 & 3.00 \\
& & & & 250.00 \\
& & & & 45.00
\end{tabular}

shows the homogenous distribution of the residues on the " 0 " axis, and the experimental removal (\%) values are very well aligned on the Henry line, which confirmed the normality of the residues and the absence of the outliers for both molecules. ${ }^{99}$

Fig. $2 \mathrm{~S} \uparrow$ illustrates the Pareto chart which gives an idea about the most influenced factors and its interactions. ${ }^{\mathbf{1 0 0 , 1 0 1}}$ Therefore, the results presented in Fig. 2Sa $\uparrow$ shows that the interaction temperature $\times$ temperature present more than $87 \%$ of aspirin removal responses. In the case of ketoprofen adsorption, the factors adsorbent mass/temperature and their interaction influence the removal efficacy by $80 \%$. As a result, Pareto analysis demonstrated that the effect of temperature on removal responses of aspirin and ketoprofen was higher compared to other factors. This finding approved the results obtained in Section 3.4 adsorption isotherm. By increasing temperature, the adsorption capacity of both molecules decreased dramatically.

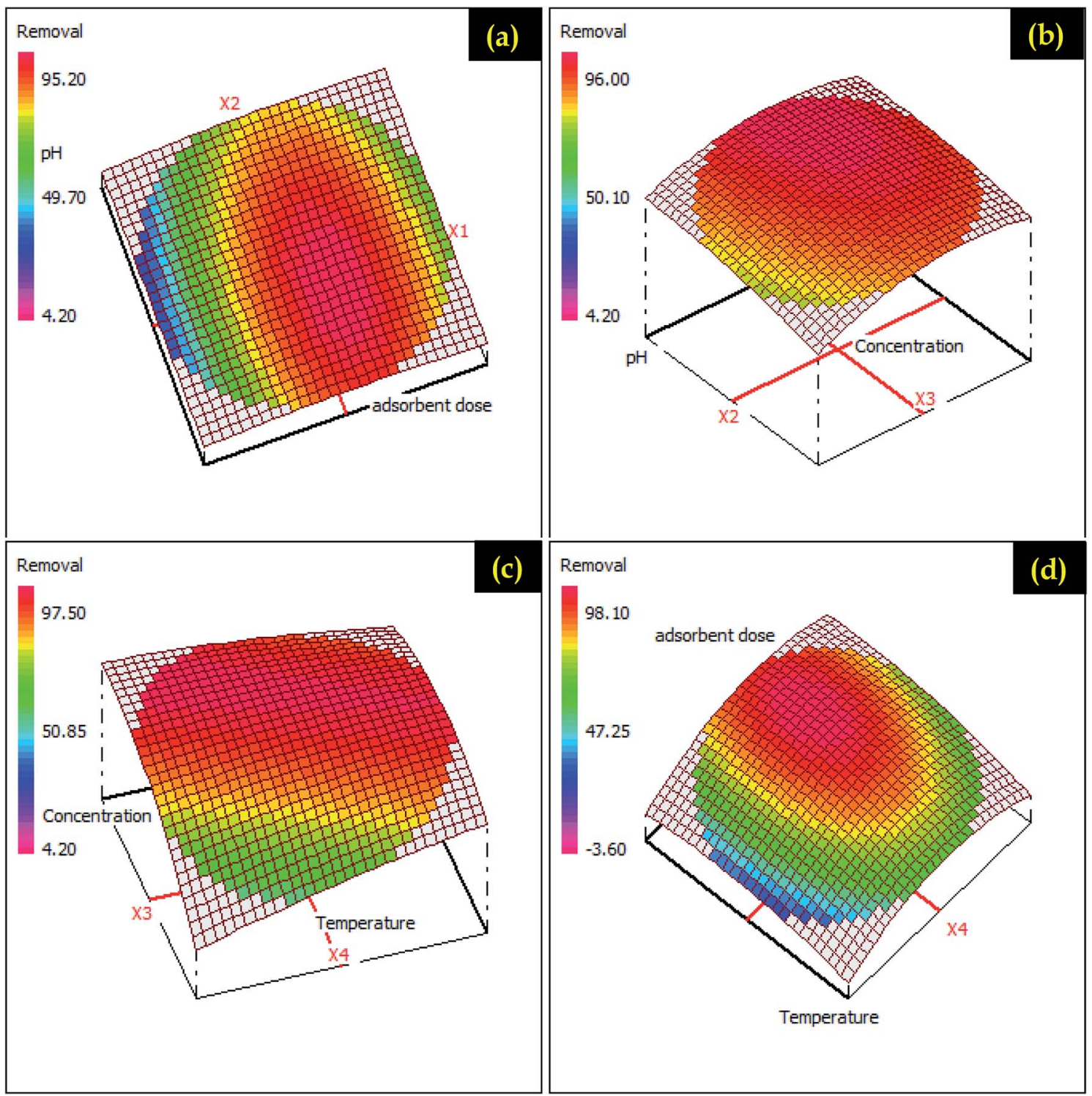

Fig. 11 RSM presentations for ketoprofen adsorption on different possible plans (a) adsorbent dose - pH (b) pH - concentration (c) concentration - temperature and (d) adsorbent dose - temperature. 


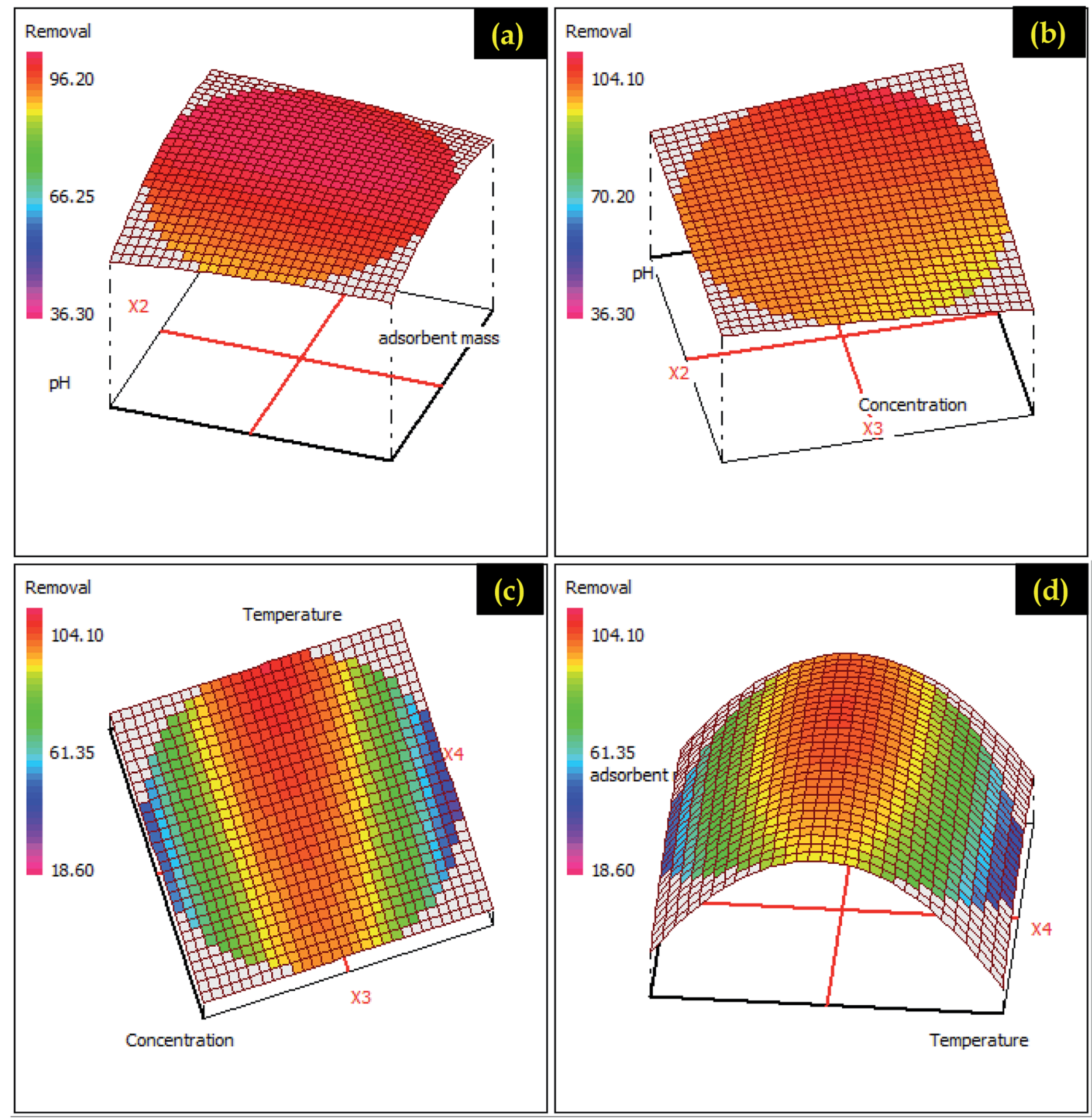

Fig. 12 RSM presentations for aspirin adsorption on different possible plans (a) adsorbent dose - pH (b) pH - concentration (c) concentration temperature and (d) adsorbent dose - temperature.

Fig. $3 \mathrm{~S}$ and $4 \mathrm{~S} \dagger$ displayed the 2D presentations for ketoprofen and aspirin adsorption in different plans. In this presentation, a response surface is a parabolic form, which shows that the significant responses are concentrated in the center of experimental domains. Indeed, the variation of $\mathrm{pH}$ from 1.4 to 5.4 with the adsorbent dose favors a considerable increase of ketoprofen and aspirin adsorption (Fig. $3 \mathrm{~S}$ and $4 \mathrm{~S} \dagger$ ). 2D presentations allow examining the variation and influence of factors and shows that the plan temperature adsorbent dose was the perfect plan for possible optimization. In addition, the RSM approach was utilized as a numerical optimization for ketoprofen and aspirin adsorption optimization (Fig. 11 and 12) based on the elaborated equations. Rendering to RSM, the optimum parameters for ketoprofen and aspirin maximum removal are cited in Table 3S. $\uparrow$ These parameters were investigated in experimental tests, and $86.12 \% \pm 4.80$ and $95.33 \% \pm$ 2.09 were achieved for ketoprofen and aspirin adsorption onto PCLD@NaOH, respectively. These outcomes proving the importance of modeling and optimization section to valorize this present work.

\section{Conclusion}

This study examined the adsorption of ketoprofen and aspirin from aqueous solution using $\mathrm{NaOH}$ modified Laminaria digitata algae (PCLD@NaOH) as an adsorbent. The PCLD@NaOH was well produced using the chemical method, and full characterized. Several factors such as ketoprofen and aspirin 
concentration, pH solution, PCLD@NaOH mass, and temperature were investigated. The adsorption of ketoprofen and aspirin on PCLD@NaOH follows the Avrami-fractional kinetic model, and the Liu isotherm model describes well the adsorption process. The maximum adsorption capacity of $970.88 \mathrm{mg}$ $\mathrm{g}^{-1}$ and $443.45 \mathrm{mg} \mathrm{g}^{-1}$ was obtained at $25{ }^{\circ} \mathrm{C}$ for aspirin and ketoprofen, respectively. The thermodynamic studies showed that the adsorption process of ketoprofen and aspirin is exothermic and spontaneous. The theoretical study by DFT calculation confirmed the experimental results through the study of ketoprofen and aspirin reactivity. Finally, based on response surface method optimization, the models predicted a maximum ketoprofen removal $(85.56 \% \pm 3.02)$ and aspirin removal $(94.97 \% \pm 1.57)$ under optimum conditions are very close to the experimental (ketoprofen: $86.12 \% \pm 4.80$; aspirin: $95.33 \% \pm 2.09$ )

\section{Conflicts of interest}

Authors declare no conflict of interest.

\section{References}

1 A. Sofowora, E. Ogunbodede and A. Onayade, Afr. J. Tradit., Complementary Altern. Med., 2013, 10, 210-229.

2 A. B. A. Boxall, EMBO Rep., 2004, 5, 1110-1116.

3 D. Fatta-Kassinos, S. Meric and A. Nikolaou, Anal. Bioanal. Chem., 2011, 399, 251-275.

4 S. Caroli and A. B. Caracciolo, Toxicol. Environ. Chem., 2010, 92, 549-565.

5 S. Kar, K. Roy and J. Leszczynski, in Impact of Pharmaceuticals on the Environment: Risk Assessment Using QSAR Modeling Approach, ed. O. Nicolotti, Springer New York, New York, NY, 2018, pp. 395-443.

6 K. Fent, A. A. Weston and D. Caminada, Aquat. Toxicol., 2006, 76, 122-159.

7 M. Liebig, J. F. Moltmann and T. Knacker, Environ. Sci. Pollut. Res. Int., 2006, 13, 110-119.

8 N. Nakada, T. Tanishima, H. Shinohara, K. Kiri and H. Takada, Water Res., 2006, 40, 3297-3303.

9 A. Tauxe-Wuersch, L. F. De Alencastro, D. Grandjean and J. Tarradellas, Water Res., 2005, 39, 1761-1772.

10 Y.-J. Liu, S.-L. Lo, Y.-H. Liou and C.-Y. Hu, Sep. Purif. Technol., 2015, 152, 148-154.

11 T. Kosjek, E. Heath and A. Krbavčič, Environ. Int., 2005, 31, 679-685.

12 A. Togola and H. Budzinski, J. Chromatogr. A, 2008, 1177, 150-158.

13 M. D. Hernando, E. Heath, M. Petrovic and D. Barceló, Anal. Bioanal. Chem., 2006, 385, 985-991.

14 M. J. Ahmed and B. H. Hameed, J. Cleaner Prod., 2018, 195, 1162-1169.

15 L. M. Madikizela, S. F. Muthwa and L. Chimuka, S. Afr. J. Chem., 2014, 67, 143-150.

16 F. O. Agunbiade and B. Moodley, Environ. Toxicol. Chem., 2016, 35, 36-46.
17 S. S. Zunngu, L. M. Madikizela, L. Chimuka and P. S. Mdluli, C. R. Chim., 2017, 20, 585-591.

18 W.-K. Jo and T. Sivakumar Natarajan, ACS Appl. Mater. Interfaces, 2015, 7, 17138-17154.

19 Y. Zeng, X. Lin, F. Li, P. Chen, Q. Kong, G. Liu and W. Lv, RSC Adv., 2018, 8, 10541-10548.

20 A. F. Martins, C. A. Mallmann, D. R. Arsand, F. M. Mayer and C. G. B. Brenner, Clean: Soil, Air, Water, 2011, 39, 21-27.

21 W.-L. Chou, C.-T. Wang, K.-Y. Huang and T.-C. Liu, Desalination, 2011, 271, 55-61.

22 N. Ouasfi, S. Bouzekri, M. Zbair, H. Ait Ahsaine, S. Bakkas, M. Bensitel and L. Khamliche, Surf. Interfaces, 2019, 14, 6171.

23 N. Zhuo, Y. Lan, W. Yang, Z. Yang, X. Li, X. Zhou, Y. Liu, J. Shen and X. Zhang, Sep. Purif. Technol., 2017, 177, 272280.

24 Z. Hasan, E. J. Choi and S. H. Jhung, Chem. Eng. J., 2013, 219, 537-544.

25 J. Y. Song, B. N. Bhadra and S. H. Jhung, Microporous Mesoporous Mater., 2017, 243, 221-228.

26 M. Zbair, K. Ainassaari, Z. El Assal, S. Ojala, N. El Ouahedy, R. L. Keiski, M. Bensitel and R. Brahmi, Environ. Sci. Pollut. Res., 2018, 25, 35657-35671.

27 M. Zbair, K. Ainassaari, A. Drif, S. Ojala, M. Bottlinger, M. Pirilä, R. L. Keiski, M. Bensitel and R. Brahmi, Environ. Sci. Pollut. Res., 2018, 25, 1869-1882.

28 X. Zhang, C. Qin, Y. Gong, Y. Song, G. Zhang, R. Chen, Y. Gao, L. Xiao and S. Jia, RSC Adv., 2019, 9, 5313-5324.

29 Z. Li, L. Chen, Q. Su, L. Wu, X. Wei, L. Zeng and M. Li, RSC Adv., 2019, 9, 5110-5120.

30 W. Kong and J. Liu, RSC Adv., 2019, 9, 4925-4931.

31 H. N. Tran, S.-J. You and H.-P. Chao, J. Environ. Manage., 2017, 188, 322-336.

32 M. T. Vu, H.-P. Chao, T. Van Trinh, T. T. Le, C.-C. Lin and H. N. Tran, J. Cleaner Prod., 2018, 180, 560-570.

33 M. Zbair, Z. Anfar and H. A. Ahsaine, RSC Adv., 2019, 9, 1084-1094.

34 H. Ait Ahsaine, M. Zbair, Z. Anfar, Y. Naciri, R. El haouti, N. El Alem and M. Ezahri, Materials Today Chemistry, 2018, 8, 121-132, DOI: 10.1016/j.mtchem.2018.03.004.

35 I. Anastopoulos and G. Z. Kyzas, J. Mol. Liq., 2015, 209, 7786.

36 P. Boakye, H. N. Tran, D. S. Lee and S. H. Woo, J. Environ. Manage., 2019, 233, 165-174.

37 M. Bilal, T. Rasheed, J. E. Sosa-Hernández, A. Raza, F. Nabeel and H. M. N. Iqbal, Mar. Drugs, 2018, 16, 65.

38 S. Wang, M. F. Hamza, T. Vincent, C. Faur and E. Guibal, J. Colloid Interface Sci., 2017, 504, 780-789.

39 S. K. Papageorgiou, E. P. Kouvelos and F. K. Katsaros, Desalination, 2008, 224, 293-306.

40 H. N. Tran, H.-P. Chao and S.-J. You, Adsorpt. Sci. Technol., 2017, 36, 95-113.

41 J. Wang, C. P. Huang, H. E. Allen, D. K. Cha and D. W. Kim, J. Colloid Interface Sci., 1998, 208, 518-528.

42 V. K. Garg, R. Gupta, A. B. Yadav and R. Kumar, Bioresour. Technol., 2003, 89, 121-124.

43 S. Lagergren, K. Sven. Vetenskapsakad. Handl., 1898, 24, 1. 
44 G. McKay, Process Biochem., 1999, 34, 451.

45 É. C. Lima, M. A. Adebayo and F. M. Machado, in Carbon Nanomaterials as Adsorbents for Environmental and Biological Applications, ed. C. P. Bergmann and F. M. Machado, Springer International Publishing, Cham, 2015, pp. 33-69.

46 J. C. Weber and W. J. Morris, J. Sanit. Eng. Div., Am. Soc. Civ. Eng., 1963, 89, 31-60.

47 I. Langmuir, J. Am. Chem. Soc., 1916, 38, 2221-2295.

48 C. Saucier, M. A. Adebayo, E. C. Lima, L. D. T. Prola, P. S. Thue, C. S. Umpierres, M. J. Puchana-Rosero and F. M. Machado, Clean: Soil, Air, Water, 2015, 43, 1389-1400.

49 H. Freundlich, Z. Phys. Chem., 1906, 57A, 385.

50 E. C. Lima, A. Hosseini-Bandegharaei, J. C. Moreno-Piraján and I. Anastopoulos, J. Mol. Liq., 2019, 273, 425-434.

51 I. Anastopoulos and G. Z. Kyzas, J. Mol. Liq., 2016, 218, 174185.

52 P. S. Ghosal and A. K. Gupta, J. Mol. Liq., 2017, 225, 137-146. 53 A. D. Becke, J. Chem. Phys., 1993, 98, 5648-5652.

54 H. Ullah, A.-H. A. Shah, K. Ayub and S. Bilal, J. Phys. Chem. C, 2013, 117, 4069-4078.

55 U. Eduok, O. Faye and J. Szpunar, RSC Adv., 2016, 6, 108777-108790.

56 T. N. V. de Souza, S. M. L. de Carvalho, M. G. A. Vieira, M. G. C. da Silva and D. do S. B. Brasil, Appl. Surf. Sci., 2018, 448, 662-670.

57 Y.-C. Chiang, W.-H. Lin and Y.-C. Chang, Appl. Surf. Sci., 2011, 257, 2401-2410.

58 R. Chulliyote, H. Hareendrakrishnakumar, M. Raja, J. M. Gladis and A. M. Stephan, ChemistrySelect, 2017, 2, 10484-10495.

59 Y.-C. Chiang, Y.-J. Chen and C.-Y. Wu, Materials, 2017, 10, 1296.

60 J. Baltrusaitis, P. M. Jayaweera and V. H. Grassian, Phys. Chem. Chem. Phys., 2009, 11, 8295-8305.

61 R. Shokri Khoubestani, N. Mirghaffari and O. Farhadian, Environ. Prog. Sustainable Energy, 2015, 34, 949-956.

62 A. Bello, N. Manyala, F. Barzegar, A. A. Khaleed, D. Y. Momodu and J. K. Dangbegnon, RSC Adv., 2016, 6, 1800-1809.

63 M. Zbair, H. A. Ahsaine and Z. Anfar, J. Cleaner Prod., 2018, 202, 571-581.

64 V. Bernal, L. Giraldo and J. C. Moreno-Piraján, Adsorpt. Sci. Technol., 2017, 36, 833-850.

65 X. Ling, H. Li, H. Zha, C. He and J. Huang, Chem. Eng. J., 2016, 286, 400-407.

66 A. J. B. Leite, A. C. Sophia, P. S. Thue, G. S. dos Reis, S. L. Dias, E. C. Lima, C. P. J. Vaghetti, F. A. Pavan and W. S. de Alencar, Desalin. Water Treat., 2017, 71, 168-181.

67 F. M. Kasperiski, E. C. Lima, C. S. Umpierres, G. S. dos Reis, P. S. Thue, D. R. Lima, S. L. P. Dias, C. Saucier and J. B. da Costa, J. Cleaner Prod., 2018, 197, 919-929.

68 P. S. Thue, M. A. Adebayo, E. C. Lima, J. M. Sieliechi, F. M. Machado, G. L. Dotto, J. C. P. Vaghetti and S. L. P. Dias, J. Mol. Liq., 2016, 223, 1067-1080.
69 C. Saucier, P. Karthickeyan, V. Ranjithkumar, E. C. Lima, G. S. dos Reis and I. A. S. de Brum, Environ. Sci. Pollut. Res., 2017, 24, 5918-5932.

70 A. Sharma, Z. Syed, U. Brighu, A. B. Gupta and C. Ram, J. Cleaner Prod., 2019, 220, 23-32.

71 A. G. N. Wamba, E. C. Lima, S. K. Ndi, P. S. Thue, J. G. Kayem, F. S. Rodembusch, G. S. dos Reis and W. S. de Alencar, Environ. Sci. Pollut. Res., 2017, 24, 21807-21820.

72 L. D. T. Prola, F. M. Machado, C. P. Bergmann, F. E. de Souza, C. R. Gally, E. C. Lima, M. A. Adebayo, S. L. P. Dias and T. Calvete, J. Environ. Manage., 2013, 130, 166-175.

73 G. M. S. El Shafei and N. A. Moussa, J. Colloid Interface Sci., 2001, 238, 160-166.

74 B. Belhamdi, Z. Merzougui, M. Trari and A. Addoun, J. Appl. Res. Technol., 2016, 14, 354-366.

75 N. Y. Mlunguza, P. S. Mdluli, S. S. Zunngu, L. M. Madikizela, N. T. Tavengwa and L. Chimuka, Water SA, 2018, 44, 406.

76 R. Baccar, M. Sarrà, J. Bouzid, M. Feki and P. Blánquez, Chem. Eng. J., 2012, 211-212, 310-317.

77 J. Y. Song and S. H. Jhung, Chem. Eng. J., 2017, 322, 366-374.

78 F. Liu, J. Zhao, S. Wang, P. Du and B. Xing, Environ. Sci. Technol., 2014, 48, 13197-13206.

79 S. Wong, Y. Lee, N. Ngadi, I. M. Inuwa and N. B. Mohamed, Chin. J. Chem. Eng., 2018, 26, 1003-1011.

80 M. T. Mupa M, J. Environ. Anal. Toxicol., 2015, s7, 1-9.

81 K. Mphahlele, M. S. Onyango and S. D. Mhlanga, J. Environ. Chem. Eng., 2015, 3, 2619-2630.

82 L. A. Al-Khateeb, S. Almotiry and M. A. Salam, Chem. Eng. J., 2014, 248, 191-199.

83 H. N. Tran, S. J. You, A. Hosseini-Bandegharaei and H. P. Chao, Water Res., 2017, 120, 88-116.

84 H. N. Tran, S.-J. You and H.-P. Chao, J. Environ. Chem. Eng., 2016, 4, 2671-2682.

85 M. Zbair, M. Bottlinger, K. Ainassaari, S. Ojala, O. Stein, R. L. Keiski, M. Bensitel and R. Brahmi, Waste Biomass Valorization, 2018, 1-20.

86 M. Zbair, Z. Anfar and H. A. Ahsaine, RSC Adv., 2019, 9, 5756-5769.

87 H. N. Tran, S.-J. You and H.-P. Chao, J. Environ. Manage., 2017, 188, 322-336.

88 R. W. Coughlin and F. S. Ezra, Environ. Sci. Technol., 1968, 2, 291-297.

89 H. N. Tran, S.-J. You and H.-P. Chao, Korean J. Chem. Eng., 2017, 34, 1708-1720.

90 K. Fukui, Angew. Chem., Int. Ed. Engl., 1982, 21, 801-809.

91 L. R. Domingo, M. J. Aurell, P. Pérez and R. Contreras, Tetrahedron, 2002, 58, 4417-4423.

92 R. G. Parr, L. v. Szentpály and S. Liu, J. Am. Chem. Soc., 1999, 121, 1922-1924.

93 Z. Anfar, M. Zbair, H. A. Ahsaine, M. Ezahri and N. E. Alem, Fullerenes, Nanotubes, Carbon Nanostruct., 2018, 26, 389397.

94 M. Zbair, Z. Anfar, H. Ait Ahsaine, N. El Alem and M. Ezahri, J. Environ. Manage., 2018, 206, 383-397, DOI: 10.1016/ j.jenvman.2017.10.058. 
95 M. Zbair, Z. Anfar, H. Khallok, H. A. Ahsaine, M. Ezahri and N. Elalem, Fullerenes, Nanotubes, Carbon Nanostruct., 2018, 26, 433-442.

96 A. Dargahi, A. Ansari, D. Nematollahi, G. Asgari, R. Shokoohia and M. R. Samarghandi, RSC Adv., 2019, 9, 5064-5075.

97 E. Sharifpour, E. Alipanahpour Dil, A. Asfaram, M. Ghaedi and A. Goudarzi, Appl. Organomet. Chem., 2019, e4768.
98 H. Ait Ahsaine, Z. Anfar, M. Zbair, M. Ezahri and N. El Alem, Journal of Chemistry, 2018, 2018, 14, DOI: 10.1155/2018/ 6982014.

99 M. Ș. Tanyildizi, Chem. Eng. J., 2011, 168, 1234-1240.

100 G. S. dos Reis, T. C. de A. Silva, E. C. Lima, M. Wilhelm, S. M. A. G. U. de Souza, K. Rezwan and C. H. Sampaio, Appl. Therm. Eng., 2015, 93, 590-597.

101 M. E. R. Carmona, M. A. P. Da Silva and S. G. Ferreira Leite, Process Biochem., 2005, 40, 779-788. 